\title{
Genome-wide identification and characterization of MADS-box family genes related to organ development and stress resistance in Brassica rapa
}

Gopal Saha ${ }^{1+}$, Jong-In Park ${ }^{1 \dagger}$, Hee-Jeong Jung ${ }^{1}$, Nasar Uddin Ahmed ${ }^{1}$, Md. Abdul Kayum ${ }^{1}$, Mi-Young Chung ${ }^{2}$, Yoonkang Hur ${ }^{3}$, Yong-Gu Cho ${ }^{4}$, Masao Watanabe ${ }^{5}$ and III-Sup Nou ${ }^{{ }^{*}}$

\begin{abstract}
Background: MADS-box transcription factors (TFs) are important in floral organ specification as well as several other aspects of plant growth and development. Studies on stress resistance-related functions of MADS-box genes are very limited and no such functional studies in Brassica rapa have been reported. To gain insight into this gene family and to elucidate their roles in organ development and stress resistance, we performed genome-wide identification, characterization and expression analysis of MADS-box genes in B. rapa.

Results: Whole-genome survey of $B$. rapa revealed 167 MADS-box genes, which were categorized into type I $\left(\mathrm{Ma}, \mathrm{M} \beta\right.$ and $\mathrm{MY}$ ) and type II (MIKC ${ }^{C}$ and $\left.\mathrm{MIKC}^{*}\right)$ based on phylogeny, protein motif structure and exon-intron organization. Expression analysis of $89 \mathrm{MIKC}^{\mathrm{C}}$ and $11 \mathrm{MIKC}^{*}$ genes was then carried out. In addition to those with floral and vegetative tissue expression, we identified MADS-box genes with constitutive expression patterns at different stages of flower development. More importantly, from a low temperature-treated whole-genome microarray data set, 19 BrMADS genes were found to show variable transcript abundance in two contrasting inbred lines of B. rapa. Among these, 13 BrMADS genes were further validated and their differential expression was monitored in response to cold stress in the same two lines via qPCR expression analysis. Additionally, the set of 19 BrMADS genes was analyzed under drought and salt stress, and 8 and 6 genes were found to be induced by drought and salt, respectively.

Conclusion: The extensive annotation and transcriptome profiling reported in this study will be useful for understanding the involvement of MADS-box genes in stress resistance in addition to their growth and developmental functions, which ultimately provides the basis for functional characterization and exploitation of the candidate genes for genetic engineering of B. rapa.
\end{abstract}

Keywords: MADS-box, Type I, Type II, MIKC' , Organ development, Abiotic stress, Brassica rapa

\footnotetext{
*Correspondence: nis@sunchon.ac.kr

†Equal contributors

'Department of Horticulture, Sunchon National University, 413 Jungangno,

Suncheon, Jeonnam 540-742, Republic of Korea

Full list of author information is available at the end of the article
} 


\section{Background}

MADS-box genes play important roles in many aspects of plant development [1]. They are the major components in the well-known 'ABC' model that describes their roles in floral organ development [2]. MADS-box genes were identified initially as floral homeotic genes and are some of the most extensively studied transcription factors (TFs) involved in developmental control [3-5]. MADS-box proteins are characterized by the presence in the $\mathrm{N}$-terminal region of a conserved MADSbox DNA-binding domain of approximately 58-60 amino acids that binds to so-called $C A r G$ boxes (CC[A/ T] $]_{6}$ GG) [6].

Plant MADS-box genes have been subdivided into two main groups viz. M-type, also designated as type I, and MIKC, also known as type II [7]. The M-type MADSbox genes are grouped into $M \alpha, M \beta$ and $M \gamma$ based on phylogenetic relationships within their MADS-box regions [4]. The MIKC genes are characterized by the presence of keratin-like (K) domain and are classified as either MIKC ${ }^{\mathrm{C}}$ or MIKC*-type [8]. The MIKC ${ }^{\mathrm{C}}$ genes are further partitioned into 14 clades based on phylogeny [9].

MIKC-type proteins generally contain four common domains. In addition to the MADS (M) domain, MIKC proteins contain intervening (I), $\mathrm{K}$ and $\mathrm{C}$-terminal (C) domains $[10,11]$. The I domain is relatively less conserved, and contributes to the DNA binding specificity and dimerization of these proteins [12]. The $\mathrm{K}$ domain is characterized by a coiled-coil structure that mainly functions in the dimerization of MADS-box proteins. The $\mathrm{K}$ domain, which is present in MIKC MADS-box proteins but absent from M-type proteins, is more highly conserved than the I domain [4,13], and the MIKC* group has longer I domains and less conserved $\mathrm{K}$ domains than the MIKC $C^{\mathrm{C}}$ group [8]. The $\mathrm{C}$ domain, which is the least conserved, plays important roles in transcriptional activation and the formation of multimeric MADS-box protein complexes [14].

The most remarkable feature of the MADS-box gene family is the divergent functions of its members in different aspects of plant growth and development, such as flowering time control, meristem identity, floral organ identity, formation of the dehiscence zone, fruit ripening, embryo development and the development of vegetative organs such as roots and leaves [7,15-17]. Previous reports revealed the role of $M I K C^{\mathrm{C}}$ in reproductive organ development of higher plants, and this has been the well-characterized group of MADS-box proteins in plants. To date, MIKC ${ }^{\mathrm{C}}$ genes have been found to play fundamental roles in flowering time (SOC1 (SUPPRESSOR OF OVERESPRESSION OF CONSTANS1), FLC1 (FLOWERING LOCUS C), AGL24 (AGAMOUS-LIKE GENE 24), MAF1/ FLM (MADS AFFECTING FLOWERING) and SVP (SHORT VEGETATIVE PHASE); [18]); floral meristem identity (AP1 (APETALA 1), FUL (FRUITFUL) and CAL (CAULIFLOWER); [19]); the formation of floral organs (AP1, SEP1-3 (SEPALLATA 1-3), AP3 (APETALA 3), PI (PISTILLATA) and AG (AGAMOUS); [20]); fruit ripening (SHP1, SHP2 (SHATTERPROOF 1-2) and FUL; $[21,22])$ and seed pigmentation and embryo development (TT16 (TRANSPARENT TESTA16); [23]).

The biological functions of MIKC ${ }^{\mathrm{c}}$ genes in flower organogenesis can be grouped into five classes, $A, B, C, D$ and $E$, which are required in different combinations to specify the identity of sepals $(A+E)$, petals $(A+B+E)$, stamens $(B+C+E)$, carpels $(C+E)$ and ovules $(D+E)$ $[20,24,25]$. Expression of MIKC ${ }^{\mathrm{C}}$ genes has also been detected outside reproductive organs, e.g., of genes belonging to the AGL12 and AGL17 subfamilies [1,26]. This expression suggested a role for those genes in vegetative development, which was later demonstrated for some of them in root development. Nevertheless, AGL12 and AGL17 have been proposed to play roles as flowering promoters [27]. By contrast, M-type (type I) MADS-box genes in Arabidopsis appear to function exclusively during female gametophyte and seed development [28].

The genus Brassica includes a number of important crops that provide oil, vegetables, condiments, dietary fiber, and vitamin C [29]. Among Brassica species, Brassica rapa comprises several subspecies, including Chinese cabbage (B. rapa ssp. pekinensis), non-heading Chinese cabbage (B. rapa ssp. chinensis) and turnip (B. rapa ssp. rapifera). Chinese cabbage is one of the most important vegetables in Asia. In addition, B. rapa is used as the model species representing the Brassica 'A' genome and, therefore, was selected for genome sequencing [30,31]. This species has already proven a useful model for studying polyploidy, in part because it has a relatively small genome [approximately 529 megabase pairs (Mbp)] compared to other Brassica species. Comparative genomic analysis confirmed that $B$. rapa underwent genome triplication since its divergence from Arabidopsis [32]. MADSbox family genes have been thoroughly studied in its close relative Arabidopsis, but have not been characterized in the relatively large and complex genome of B. rapa. Over the course of evolution, the number of genes in this family steadily increased as the reproductive system became more complex; concomitant with this expansion of the lineage, MADS-box genes have been found to perform more diversified functions [33]. In addition to growth and development-related functions, some stress-responsive MADS-box genes have also been reported in wheat and rice $[34,35]$. As an important vegetable crop worldwide, Brassica species are subject to a variety of abiotic stresses. Identification of stress-resistance-related MADSbox genes in Brassica could be highly useful.

The recent sequencing of the Brassica rapa ssp. pekinensis genome [36] offers the possibility of genome-wide 
analysis of MADS-box genes. In this study, we analyzed the genomic localization, protein motif structure, phylogenetic relationships, and gene structure of all candidate MADS-box genes in B. rapa. We carried out extensive expression profiling for specific $M I K C^{\mathrm{C}}$ subfamilies in vegetative and reproductive organs, as well as during flower developmental stages. Additionally, we investigated a considerable number of MADS-box genes, selected from whole-genome, low temperature-treated microarray data in the cold-tolerant and -susceptible inbred lines of B. rapa, Chiifu and Kenshin, respectively.

\section{Results \\ Identification and sequence analysis of MADS-box genes in B. rapa}

A set of 167 candidate MADS-box genes from the $B$. rapa genome was recovered using key word 'MADS-box' to search Swissprot annotations at the Brassica database (BRAD) (http://brassicadb.org/brad/) [37]. This number of candidates $B$. rapa (167) is higher than the number of MADS-box genes in Arabidopsis, rice, soybean, maize and sorghum (Additional file 1: Table S1) [4,35,38,39]. A domain search using EMBL (http://smart.embl.de/smart/ set_mode.cgi?GENOMIC=1) with the corresponding $B$. rapa candidate protein sequences confirmed 162 of them to contain a 'MADS' domain, whereas the other 5 did not. The five candidates (BrMADS85, 87, 89, 119 and 127) that lacked a 'MADS' domain shared considerable sequence similarity with MADS-box proteins of other crop species that also lack 'MADS' domains and are considered to be MADS-box proteins (4 published and 1 unpublished MADS-box genes; Additional file 1: Table S2). We classified all 167 putative $B$. rapa MADS-box proteins into five classes (i. e., MIKC ${ }^{\mathrm{c}}$ and $\mathrm{MIKC}$ of type II and $\mathrm{M} \alpha, \mathrm{M} \beta$ and $\mathrm{M} \gamma$ of type I) in accord with the previously reported classification of the MADS-box family members in flowering plants [4]. We designated the 167 annotated MADSbox genes of $B$. rapa as $B r M A D S$ followed by Arabic numbers 1-167, consecutively following the five classes (MIKC $C^{\mathrm{C}}, \mathrm{MIKC}^{*}, \mathrm{M} \alpha, \mathrm{M} \beta$ and $\mathrm{M} \gamma$ ). Subsequent sequence analysis of the 167 genes showed open reading frame (ORFs) ranging from 180 to 2379 bp and predicted protein lengths from 59 to 792 amino acid (data not shown). Sequence analysis also revealed that B. rapa MIKC (type II) MADS-box genes usually contained multiple introns, with a maximum of 15 introns; the exceptions were BrMADS84, BrMADS86 and BrMADS88, which did not have any introns. Almost all of the M-type (type I) genes lacked introns or had only a single intron; however, M-type MADS-box genes BrMADS109 and BrMADS119 had 3 and 2 introns respectively (Table 1 and Additional file 2: Figure S2). These features are consistent with those of MADS-box genes in other flowering plants such as Arabidopsis, rice, grapevine, and soybean $[4,13,35,38]$.

\section{Phylogenetic analysis of MADS-box genes in $B$. rapa}

Independent phylogenetic trees for M-type and MIKCtype MADS-box TFs were constructed using the $B$. rapa MADS-box proteins along with those from Arabidopsis and rice. There were $67 \mathrm{M}$-type members (i.e., $\mathrm{M} \alpha, \mathrm{M} \beta$ and $\mathrm{M} \gamma$ ) from $B$. rapa, with the other 100 proteins belonging to MIKC-type (MIKC ${ }^{\mathrm{C}}$ and MIKC"; Figure 1). Notably, the MIKC $C^{\mathrm{C}}$ family included 89 members of this latter group, more than in Arabidopsis, rice, and soybean (Additional file 1: Table S1). Among the $89 \mathrm{MIKC}^{\mathrm{C}}$ genes, BrMADS84, 86, 87, 88 and 89 could not be assigned in the tree using the bootstrap method with 1000 replicates, possibly due to high sequence divergence in the conserved regions and sequence length. To test their relationships and relevance with other MADS-box genes, we generated an alternative phylogenetic tree without using bootstrap replications and found these five genes in the different clades of MIKC ${ }^{\mathrm{C}}$ (Additional file 2: Figure S1b).

In accordance with the known classes of Arabidopsis MADS-box genes, we found $13 \mathrm{MIKC}^{\mathrm{C}}$ clades in B. rapa. Although most of the B. rapa MADS-box genes were consistent with Arabidopsis in terms of sequence similarity and grouping, we found some genes viz. BrMADS41, 47, 167, that were placed as close sisters of rice MADS-box genes in the tree. Interestingly, OsMADS59, instead of being included in the AGL15-like clade, paired with BrMADS47 in the TM3 clade. There was some disparity in the distribution of rice $M \beta$ genes between the two phylogenetic trees prepared with the different methods (Figure 1a and Additional file 2: Figure S1a). Among the 13 MIKC ${ }^{\mathrm{C}}$ clades, the TM3 clade contained the most $B$. rapa sequences (18). The FLC clade included three previously identified FLC genes of $B$. rapa viz. BrFLC1, BrFLC2, BrFLC3 [40] which showed 99.51, 100 and 100\% similarity to $\operatorname{BrMADS13}, 12$ and 14 respectively at the amino acid level. MIKC*/M $\delta$ included 11 members, which is almost double that in Arabidopsis (6), rice (5) and soybean (5).

In case of type I MADS-box proteins, the $\mathrm{M} \alpha$ and $\mathrm{M} \gamma$ groups had more members in $B$. rapa (29 and 22 respectively), than in Arabidopsis, rice and soybean. By contrast, the $16 \mathrm{M} \beta$ genes found in $B$. rapa was less than that in Arabidopsis, but more than in rice and soybean (Additional file 1: Table S1) [4,35,38].

\section{Analysis of conserved motifs in MADS-box proteins of B. rapa}

Ten conserved motifs among related proteins were identified from the 167 candidate MADS-box genes of $B$. rapa using the MEME (Multiple Em for Motif Elicitation) motif search tool (Figure 2 and Additional file 2: Figure S3). Motifs 1 and 6 specifying the MADS domain were found in 153 members of the MADS-box family whereas BrMADS79, 85, 87, 89, 105, 109, 113, 118,119, 127, 129, 
Table 1 In silico analysis of 167 MADS-box genes identified in B. rapa with their closest Arabidopsis homologs and sequence characteristics (aa, amino acids; Kda, Kilo dalton)

\begin{tabular}{|c|c|c|c|c|c|c|c|c|}
\hline \multirow[t]{2}{*}{ SI no. } & \multirow{2}{*}{$\begin{array}{l}\text { Gene } \\
\text { name }\end{array}$} & \multirow{2}{*}{$\begin{array}{l}\text { Gene } \\
\text { locus }\end{array}$} & \multirow[t]{2}{*}{ Chr. no. } & \multirow{2}{*}{$\begin{array}{l}\text { Closest arabidopsis } \\
\text { homolog }\end{array}$} & \multicolumn{2}{|l|}{ Protein } & \multirow{2}{*}{$\begin{array}{l}\text { No. of } \\
\text { introns }\end{array}$} & \multirow[t]{2}{*}{ Group } \\
\hline & & & & & Length (aa) & Mol.wt. (Kda) & & \\
\hline 1 & BrMADS1 & Bra040348 & A08 & $A G L 18$ & 293 & 32.69 & 5 & $\overline{\text { MIKC }^{C}}$ \\
\hline 2 & BrMADS2 & Bra014628 & A04 & AGL18 & 250 & 28.02 & 7 & MIKC C \\
\hline 3 & BrMADS3 & Bra007324 & A09 & AGL18 & 255 & 28.59 & 7 & MIKC C \\
\hline 4 & BrMADS4 & Bra019018 & A06 & AGL18 & 200 & 22.90 & 6 & MIKC \\
\hline 5 & BrMADS5 & Bra008802 & $\mathrm{A} 10$ & AGL15 & 264 & 30.13 & 7 & MIKC C \\
\hline 6 & BrMADS6 & Bra006214 & A03 & AGL15 & 264 & 30.00 & 7 & MIKC ${ }^{C}$ \\
\hline 7 & BrMADS7 & Bra031888 & $\mathrm{A} 02$ & AGL69 & 178 & 19.84 & 5 & MIKC ${ }^{\mathrm{C}}$ \\
\hline 8 & BrMADS8 & Bra024350 & A06 & $A G L 27 / F L M$ & 196 & 22.43 & 6 & MIKC \\
\hline 9 & BrMADS9 & Bra031886 & $\mathrm{A} 02$ & AGL69 & 250 & 28.14 & 6 & MIKC ${ }^{C}$ \\
\hline 10 & BrMADS10 & Bra024351 & A06 & $A G L 27 / F L M$ & 200 & 22.75 & 6 & MIKC $C^{c}$ \\
\hline 11 & BrMADS11 & Bra031884 & $\mathrm{A} 02$ & AGL27/FLM & 199 & 22.80 & 6 & MIKC C \\
\hline 12 & BrMADS12 & Bra028599 & $\mathrm{A} 02$ & AGL25/FLC & 196 & 21.93 & 6 & MIKC $^{c}$ \\
\hline 13 & BrMADS13 & Bra009055 & A10 & AGL25/FLC & 206 & 22.94 & 6 & MIKC ${ }^{C}$ \\
\hline 14 & BrMADS14 & Bra006051 & $\mathrm{A} 03$ & AGL25/FLC & 197 & 21.64 & 6 & MIKC ${ }^{C}$ \\
\hline 15 & BrMADS15 & Bra022771 & $\mathrm{A} 03$ & AGL25/FLC & 143 & 16.04 & 4 & MIKC ${ }^{C}$ \\
\hline 16 & BrMADS16 & Bra039921 & A09 & AGL17 & 227 & 26.38 & 6 & MIKC ${ }^{C}$ \\
\hline 17 & BrMADSI7 & Bra030222 & A04 & AGL17 & 227 & 26.18 & 6 & MIKC ${ }^{C}$ \\
\hline 18 & BrMADS18 & Bra011797 & $\mathrm{A} 01$ & $A G L 21$ & 228 & 33.78 & 6 & MIKC \\
\hline 19 & BrMADS19 & Bra010623 & A08 & AGL21 & 214 & 24.65 & 5 & MIKC ${ }^{C}$ \\
\hline 20 & BrMADS20 & Bra017638 & $\mathrm{A} 03$ & AGL16 & 240 & 27.51 & 6 & MIKC ${ }^{C}$ \\
\hline 21 & BrMADS21 & Bra011509 & A01 & AGL16 & 290 & 40.19 & 6 & MIKC \\
\hline 22 & BrMADS22 & Bra038511 & A09 & AGL22/SVP & 241 & 27.31 & 8 & MIKC \\
\hline 23 & BrMADS23 & Bra030228 & A04 & AGL22/SVP & 236 & 26.78 & 7 & MIKC ${ }^{\mathrm{C}}$ \\
\hline 24 & BrMADS24 & Bra019221 & $\mathrm{A} 03$ & AGL24 & 216 & 24.55 & 6 & MIKC \\
\hline 25 & BrMADS25 & Bra013812 & A01 & AGL24 & 792 & 88.94 & 15 & MIKC ${ }^{C}$ \\
\hline 26 & BrMADS26 & Bra029365 & $\mathrm{A} 02$ & AGL32/TT16 & 242 & 28.44 & 5 & MIKC \\
\hline 27 & BrMADS27 & Bra026507 & A01 & AGL32/TT16 & 300 & 36.72 & 7 & MIKC ${ }^{C}$ \\
\hline 28 & BrMADS28 & Bra013028 & $\mathrm{A} 03$ & AGL32/TT16 & 240 & 28.11 & 6 & MIKC ${ }^{C}$ \\
\hline 29 & BrMADS29 & Bra020093 & $\mathrm{A} 02$ & PISTILLATA & 203 & 23.38 & 5 & MIKC ${ }^{C}$ \\
\hline 30 & BrMADS30 & Bra006549 & $\mathrm{A} 03$ & PISTILLATA & 208 & 24.05 & 4 & MIKC \\
\hline 31 & BrMADS31 & Bra002285 & A10 & PISTILLATA & 146 & 16.62 & 3 & MIKC $^{c}$ \\
\hline 32 & BrMADS32 & Bra014822 & A04 & APETALA3 & 224 & 26.39 & 6 & MIKC ${ }^{C}$ \\
\hline 33 & BrMADS33 & Bra007067 & A09 & APETALA3 & 232 & 27.28 & 6 & MIKC C \\
\hline 34 & BrMADS34 & Bra007972 & $\mathrm{A} 02$ & AGL12 & 211 & 23.99 & 6 & MIKC \\
\hline 35 & BrMADS35 & Bra003919 & A07 & AGL12 & 212 & 24.00 & 6 & MIKC ${ }^{C}$ \\
\hline 36 & BrMADS36 & Bra039324 & A04 & AGL20/SOC1 & 213 & 24.35 & 6 & MIKC ${ }^{\mathrm{C}}$ \\
\hline 37 & BrMADS37 & Bra000393 & A03 & AGL20/SOC1 & 213 & 24.35 & 6 & MIKC ${ }^{c}$ \\
\hline 38 & BrMADS38 & Bra004928 & A05 & AGL20/SOC1 & 213 & 24.40 & 6 & MIKC C \\
\hline 39 & BrMADS39 & Bra029424 & A09 & AGL14 & 173 & 19.78 & 4 & MIKC ${ }^{C}$ \\
\hline 40 & BrMADS40 & Bra020826 & A08 & AGL19 & 146 & 16.16 & 2 & MIKC ${ }^{C}$ \\
\hline 41 & BrMADS41 & Bra013662 & A01 & AGL19 & 718 & 81.80 & 10 & MIKC ${ }^{C}$ \\
\hline 42 & BrMADS42 & Bra019343 & $\mathrm{A} 03$ & AGL19 & 219 & 25.07 & 6 & MIKC \\
\hline
\end{tabular}


Table 1 In silico analysis of 167 MADS-box genes identified in B. rapa with their closest Arabidopsis homologs and sequence characteristics (aa, amino acids; Kda, Kilo dalton) (Continued)

\begin{tabular}{|c|c|c|c|c|c|c|c|c|}
\hline$\overline{43}$ & BrMADS43 & Bra035907 & A09 & $A G L 42$ & 272 & 31.73 & 9 & $\mathrm{MIKC}^{\mathrm{C}}$ \\
\hline 44 & BrMADS44 & Bra029281 & $\mathrm{A} 02$ & AGL42 & 209 & 24.74 & 6 & MIKC \\
\hline 45 & BrMADS45 & Bra029314 & $\mathrm{A} 02$ & $A G L 72$ & 187 & 21.99 & 3 & MIKC \\
\hline 46 & BrMADS46 & Bra013891 & A01 & AGL72 & 189 & 21.94 & 3 & MIKC \\
\hline 47 & BrMADS47 & Bra010465 & A08 & AGL72 & 187 & 21.31 & 2 & $\mathrm{MIKC}^{\mathrm{C}}$ \\
\hline 48 & BrMADS48 & Bra012957 & A03 & AGL72 & 211 & 24.14 & 5 & MIKC \\
\hline 49 & BrMADS49 & Bra029155 & $\mathrm{A} 03$ & AGL72 & 209 & 23.90 & 6 & $\mathrm{MIKC}^{\mathrm{C}}$ \\
\hline 50 & BrMADS50 & Bra028282 & $\mathrm{A} 01$ & AGL72 & 202 & 23.37 & 6 & MIKC \\
\hline 51 & BrMADS51 & Bra029154 & A03 & AGL71 & 219 & 25.46 & 6 & MIKC \\
\hline 52 & BrMADS52 & Bra028283 & A01 & AGL71 & 199 & 23.05 & 5 & MIKC ${ }^{C}$ \\
\hline 53 & BrMADS53 & Bra037895 & A09 & AGL11 & 230 & 26.27 & 6 & $\mathrm{MIKC}^{\mathrm{C}}$ \\
\hline 54 & BrMADS54 & Bra000696 & $\mathrm{A} 03$ & AGL11 & 231 & 26.38 & 6 & MIKC \\
\hline 55 & BrMADS55 & Bra013364 & $\mathrm{A} 01$ & AGAMOUS & 252 & 28.78 & 6 & MIKC \\
\hline 56 & BrMADS56 & Bra012564 & $\mathrm{A} 03$ & AGAMOUS & 251 & 28.77 & 6 & MIKC \\
\hline 57 & BrMADS57 & Bra014552 & A04 & AGL1/SHP1 & 248 & 28.39 & 6 & $\mathrm{MIKC}^{\mathrm{C}}$ \\
\hline 58 & BrMADS58 & Bra003356 & A07 & AGL1/SHP1 & 273 & 31.26 & 6 & MIKC \\
\hline 59 & BrMADS59 & Bra007419 & A09 & AGL1/SHP1 & 245 & 27.76 & 6 & MIKC \\
\hline 60 & BrMADS60 & Bra004716 & A05 & AGL5/SHP2 & 244 & 28.01 & 5 & MIKC \\
\hline 61 & BrMADS61 & Bra038326 & $\mathrm{A} 02$ & AGL7/AP1 & 256 & 30.12 & 7 & $\mathrm{MIKC}^{\mathrm{C}}$ \\
\hline 62 & BrMADS62 & Bra004361 & A07 & AGL7/AP1 & 189 & 22.51 & 5 & MIKC \\
\hline 63 & BrMADS63 & Bra004007 & A07 & AGL7/AP1 & 271 & 31.67 & 8 & MIKC \\
\hline 64 & BrMADS64 & Bra035952 & A09 & AGL8/FUL & 241 & 27.50 & 7 & MIKC \\
\hline 65 & BrMADS65 & Bra029347 & $\mathrm{A} 02$ & AGL8/FUL & 240 & 27.34 & 7 & MIKC ${ }^{C}$ \\
\hline 66 & BrMADS66 & Bra012997 & $\mathrm{A} 03$ & AGL8/FUL & 241 & 27.45 & 7 & MIKC \\
\hline 67 & BrMADS67 & Bra036201 & A09 & AGL79 & 248 & 27.97 & 7 & MIKC \\
\hline 68 & BrMADS68 & Bra025411 & A06 & AGL79 & 176 & 20.25 & 5 & MIKC \\
\hline 69 & BrMADS69 & Bra020742 & $\mathrm{A} 02$ & AGL79 & 577 & 64.08 & 9 & MIKC \\
\hline 70 & BrMADS70 & Bra011021 & A08 & AGL10/CAL & 254 & 29.88 & 6 & MIKC \\
\hline 71 & BrMADS71 & Bra014454 & A04 & AGL13 & 230 & 26.21 & 6 & MIKC \\
\hline 72 & BrMADS72 & Bra004927 & A05 & AGL6 & 242 & 27.60 & 7 & MIKC \\
\hline 73 & BrMADS73 & Bra000392 & A03 & AGL6 & 257 & 29.47 & 7 & MIKC \\
\hline 74 & BrMADS74 & Bra021470 & $\mathrm{A} 01$ & $A G L 4 / S E P 2$ & 252 & 28.77 & 6 & MIKC \\
\hline 75 & BrMADS75 & Bra039170 & A05 & AGL4SEP2 & 250 & 28.57 & 6 & MIKC \\
\hline 76 & BrMADS76 & Bra010955 & $\mathrm{A} 08$ & AGL9/SEP3 & 244 & 28.21 & 7 & $\mathrm{MIKC}^{\mathrm{C}}$ \\
\hline 77 & BrMADS77 & Bra032814 & A09 & AGL9/SEP3 & 253 & 29.32 & 7 & MIKC \\
\hline 78 & BrMADS78 & Bra026543 & $\mathrm{A} 02$ & AGL3/SEP4 & 269 & 30.63 & 7 & $\mathrm{MIKC}^{\mathrm{C}}$ \\
\hline 79 & BrMADS79 & Bra017376 & A09 & AGL3/SEP4 & 243 & 27.76 & 7 & MIKC \\
\hline 80 & BrMADS80 & $\mathrm{Bra025126}$ & A06 & AGL3/SEP4 & 257 & 29.41 & 7 & MIKC \\
\hline 81 & BrMADS81 & Bra030032 & A07 & AGL9/SEP3 & 252 & 29.25 & 7 & MIKC \\
\hline 82 & BrMADS82 & Bra008674 & A10 & AGL2/SEP1 & 252 & 28.78 & 6 & MIKC \\
\hline 83 & BrMADS83 & Bra006322 & A03 & AGL2/SEP1 & 250 & 28.55 & 6 & MIKC \\
\hline 84 & BrMADS84 & Bra003278 & A07 & AGL18 & 61 & 6.91 & 0 & MIKC \\
\hline 85 & BrMADS85 & Bra003279 & $\mathrm{A} 07$ & AGL18 & 197 & 22.06 & 6 & MIKC \\
\hline 86 & BrMADS86 & Bra005545 & A05 & AGL18 & 59 & 6.90 & 0 & MIKC \\
\hline
\end{tabular}


Table 1 In silico analysis of 167 MADS-box genes identified in B. rapa with their closest Arabidopsis homologs and sequence characteristics (aa, amino acids; Kda, Kilo dalton) (Continued)

\begin{tabular}{|c|c|c|c|c|c|c|c|c|}
\hline 87 & BrMADS87 & Bra029494 & A09 & AGL15 & 118 & 13.66 & 3 & $\mathrm{MIKC}^{\mathrm{C}}$ \\
\hline 88 & BrMADS88 & Bra016128 & $\mathrm{A} 07$ & AGL12 & 62 & 7.04 & 0 & MIKC C \\
\hline 89 & BrMADS89 & Bra019163 & A03 & AGL72 & 172 & 19.64 & 4 & MIKC ${ }^{C}$ \\
\hline 90 & BrMADS90 & Bra011763 & A01 & AGL67 & 175 & 20.52 & 5 & MIKC ${ }^{*}$ \\
\hline 91 & BrMADS91 & Bra015645 & A07 & AGL67 & 209 & 24.60 & 7 & MIKC ${ }^{*}$ \\
\hline 92 & BrMADS92 & Bra012308 & A07 & AGL104 & 335 & 38.15 & 9 & $M I K C^{*}$ \\
\hline 93 & BrMADS93 & Bra016386 & A08 & AGL104 & 311 & 35.23 & 7 & MIKC $C^{*}$ \\
\hline 94 & BrMADS94 & Bra015643 & $\mathrm{A} 07$ & AGL66 & 329 & 37.59 & 8 & $M I K C^{*}$ \\
\hline 95 & BrMADS95 & Bra025685 & A06 & AGL65 & 379 & 43.18 & 9 & MIKC ${ }^{*}$ \\
\hline 96 & BrMADS96 & Bra016544 & A08 & AGL65 & 306 & 35.12 & 5 & MIKC $C^{*}$ \\
\hline 97 & BrMADS97 & Bra031049 & A09 & AGL65 & 382 & 43.92 & 9 & MIKC $C^{*}$ \\
\hline 98 & BrMADS98 & Bra024792 & A06 & AGL30 & 377 & 42.65 & 10 & $M I K C^{*}$ \\
\hline 99 & BrMADS99 & Bra017404 & A09 & AGL30 & 379 & 42.78 & 8 & MIKC ${ }^{*}$ \\
\hline 100 & BrMADS100 & Bra004393 & A07 & AGL94 & 349 & 40.09 & 7 & $M I K C^{*}$ \\
\hline 101 & BrMADS101 & Bra040149 & $\mathrm{A} 01$ & AGL57 & 174 & 19.90 & 0 & Ma \\
\hline 102 & BrMADS102 & Bra037759 & A09 & AGL58 & 190 & 21.24 & 0 & $\mathrm{Ma}$ \\
\hline 103 & BrMADS103 & Bra031945 & A02 & AGL57 & 193 & 22.17 & 0 & $\mathrm{Ma}$ \\
\hline 104 & BrMADS104 & Bra032347 & A09 & AGL64 & 186 & 20.77 & 0 & $\mathrm{Ma}$ \\
\hline 105 & BrMADS105 & Bra038225 & A01 & AGL28 & 261 & 30.31 & 1 & $\mathrm{Ma}$ \\
\hline 106 & BrMADS106 & Bra022434 & A05 & AGL62 & 283 & 32.41 & 1 & $\mathrm{Ma}$ \\
\hline 107 & BrMADS107 & Bra020242 & A02 & AGL62 & 248 & 28.09 & 1 & $\mathrm{Ma}$ \\
\hline 108 & BrMADS108 & Bra002480 & $\mathrm{A} 10$ & AGL62 & 279 & 32.06 & 1 & Ma \\
\hline 109 & BrMADS109 & Bra035685 & A04 & AGL40 & 293 & 32.84 & 3 & $\mathrm{Ma}$ \\
\hline 110 & BrMADS110 & Bra011938 & $\mathrm{A} 07$ & AGL23 & 238 & 27.09 & 1 & $\mathrm{Ma}$ \\
\hline 111 & BrMADS111 & Bra032057 & A04 & AGL61 & 180 & 20.50 & 0 & $\mathrm{Ma}$ \\
\hline 112 & BrMADS112 & Bra007829 & A09 & AGL61 & 207 & 23.13 & 0 & $\mathrm{Ma}$ \\
\hline 113 & BrMADS113 & Bra026764 & A09 & AGL62 & 168 & 19.24 & 0 & $\mathrm{Ma}$ \\
\hline 114 & BrMADS114 & Bra001209 & A03 & AGL91 & 179 & 20.33 & 0 & $\mathrm{Ma}$ \\
\hline 115 & BrMADS115 & Bra021910 & A04 & AGL29 & 182 & 20.76 & 0 & $\mathrm{Ma}$ \\
\hline 116 & BrMADS116 & Bra003884 & $\mathrm{A} 07$ & AGL60 & 212 & 24.16 & 0 & $\mathrm{Ma}$ \\
\hline 117 & BrMADS117 & Bra026674 & A09 & AGL100 & 206 & 23.59 & 0 & $\mathrm{Ma}$ \\
\hline 118 & BrMADS118 & Bra033492 & A01 & AGL84 & 293 & 32.77 & 0 & $\mathrm{Ma}$ \\
\hline 119 & BrMADS119 & Bra032767 & A04 & AGL84 & 309 & 34.32 & 2 & $\mathrm{Ma}$ \\
\hline 120 & BrMADS120 & Bra010027 & A06 & AGL73 & 345 & 38.29 & 0 & $\mathrm{Ma}$ \\
\hline 121 & BrMADS121 & Bra037434 & A06 & AGL73 & 261 & 29.19 & 0 & $\mathrm{Ma}$ \\
\hline 122 & BrMADS122 & Bra018727 & A06 & AGL74 & 245 & 27.51 & 0 & $\mathrm{Ma}$ \\
\hline 123 & BrMADS123 & Bra014217 & A08 & AGL84 & 277 & 30.41 & 0 & $\mathrm{Ma}$ \\
\hline 124 & BrMADS124 & Bra027116 & A09 & AGL55 & 243 & 27.09 & 0 & $\mathrm{Ma}$ \\
\hline 125 & BrMADS125 & Bra040965 & Scaffold000343 & AGL55 & 198 & 21.96 & - & $\mathrm{Ma}$ \\
\hline 126 & BrMADS126 & Bra009436 & $\mathrm{A} 10$ & AGL97 & 306 & 33.85 & 0 & $\mathrm{Ma}$ \\
\hline 127 & BrMADS127 & Bra038728 & $\mathrm{A} 01$ & AGL74 & 173 & 19.84 & 0 & $\mathrm{Ma}$ \\
\hline 128 & BrMADS128 & Bra020600 & $\mathrm{A} 02$ & AGL39 & 263 & 24.32 & 0 & Ma \\
\hline 129 & BrMADS129 & Bra020247 & $\mathrm{A} 02$ & AGL23 & 269 & 30.64 & 1 & $\mathrm{Ma}$ \\
\hline 130 & BrMADS130 & Bra028965 & A03 & AGL47 & 274 & 31.46 & 0 & $M \beta$ \\
\hline
\end{tabular}


Table 1 In silico analysis of 167 MADS-box genes identified in B. rapa with their closest Arabidopsis homologs and sequence characteristics (aa, amino acids; Kda, Kilo dalton) (Continued)

\begin{tabular}{|c|c|c|c|c|c|c|c|c|}
\hline 131 & BrMADS131 & Bra002611 & A10 & AGL82 & 297 & 34.61 & 0 & $M \beta$ \\
\hline 132 & BrMADS132 & Bra037571 & $\mathrm{A} 01$ & AGL103 & 342 & 39.17 & 0 & $M \beta$ \\
\hline 133 & BrMADS133 & Bra022341 & A05 & AGL103 & 368 & 42.12 & 0 & $M \beta$ \\
\hline 134 & BrMADS134 & Bra031864 & $\mathrm{A} 02$ & AGL52 & 331 & 37.76 & 0 & $M \beta$ \\
\hline 135 & BrMADS135 & Bra025619 & A04 & AGL76 & 367 & 42.32 & 0 & $M \beta$ \\
\hline 136 & BrMADS136 & $\mathrm{Bra025607}$ & $\mathrm{A} 04$ & AGL76 & 349 & 40.12 & 0 & $M \beta$ \\
\hline 137 & BrMADS137 & Bra025609 & A04 & AGL76 & 336 & 38.32 & 0 & $M \beta$ \\
\hline 138 & BrMADS138 & Bra018767 & A06 & AGL93 & 306 & 34.70 & 0 & $M \beta$ \\
\hline 139 & BrMADS139 & Bra015129 & A07 & AGL93 & 319 & 35.90 & 0 & $M \beta$ \\
\hline 140 & BrMADS140 & Bra020923 & A08 & AGL89 & 209 & 24.26 & 0 & $M \beta$ \\
\hline 141 & BrMADS141 & Bra018741 & A06 & AGL89 & 264 & 30.10 & 0 & $M \beta$ \\
\hline 142 & BrMADS142 & $\mathrm{Bra028020}$ & A09 & AGL89 & 263 & 29.76 & 1 & $M \beta$ \\
\hline 143 & BrMADS143 & Bra007138 & A09 & AGL89 & 281 & 32.09 & 0 & $M \beta$ \\
\hline 144 & BrMADS144 & Bra028019 & A09 & AGL89 & 285 & 32.59 & 0 & $M \beta$ \\
\hline 145 & BrMADS145 & Bra004071 & A07 & AGL101 & 284 & 32.33 & 0 & $M \beta$ \\
\hline 146 & BrMADS146 & Bra040248 & $\mathrm{A} 01$ & $A G L 46$ & 413 & 46.76 & 1 & My \\
\hline 147 & BrMADS147 & Bra005166 & A05 & $A G L 46$ & 125 & 14.56 & 0 & My \\
\hline 148 & BrMADS148 & Bra035448 & $\mathrm{A} 01$ & $A G L 46$ & 264 & 30.77 & 1 & My \\
\hline 149 & BrMADS149 & Bra035449 & $\mathrm{A} 01$ & $A G L 46$ & 264 & 30.80 & 1 & My \\
\hline 150 & BrMADS150 & Bra039404 & A05 & AGL45 & 302 & 34.96 & 0 & My \\
\hline 151 & BrMADS151 & Bra020555 & $\mathrm{A} 02$ & AGL35 & 216 & 24.32 & 0 & My \\
\hline 152 & BrMADS152 & Bra009913 & A06 & AGL35 & 203 & 22.78 & 0 & My \\
\hline 153 & BrMADS153 & Bra018490 & A05 & $A G L 80$ & 290 & 33.43 & 0 & My \\
\hline 154 & BrMADS154 & Bra029469 & A09 & AGL80 & 304 & 34.48 & 0 & My \\
\hline 155 & BrMADS155 & Bra041022 & Scaffold000385 & AGL80 & 334 & 36.92 & - & My \\
\hline 156 & BrMADS156 & Bra020552 & $\mathrm{A} 02$ & AGL37 & 341 & 38.45 & 0 & My \\
\hline 157 & BrMADS157 & Bra020550 & $\mathrm{A} 02$ & AGL36 & 380 & 42.85 & 0 & My \\
\hline 158 & BrMADS158 & Bra020525 & $\mathrm{A} 02$ & AGL92 & 395 & 44.76 & 0 & My \\
\hline 159 & BrMADS159 & Bra020524 & $\mathrm{A} 02$ & AGL92 & 360 & 40.86 & 0 & My \\
\hline 160 & BrMADS160 & Bra009911 & A06 & AGL92 & 364 & 41.44 & 0 & My \\
\hline 161 & BrMADS161 & Bra012335 & A07 & AGL87 & 162 & 18.99 & 0 & My \\
\hline 162 & BrMADS162 & Bra024521 & A09 & AGL87 & 162 & 18.87 & 0 & My \\
\hline 163 & BrMADS163 & Bra028730 & $\mathrm{A} 02$ & AGL96 & 252 & 28.88 & 0 & My \\
\hline 164 & BrMADS164 & Bra009199 & A10 & AGL96 & 202 & 23.13 & 0 & My \\
\hline 165 & BrMADS165 & Bra009176 & A10 & AGL96 & 192 & 21.99 & 0 & My \\
\hline 166 & BrMADS166 & Bra009174 & A10 & AGL96 & 191 & 22.01 & 0 & My \\
\hline 167 & BrMADS167 & Bra034809 & A05 & AGL95 & 353 & 40.27 & 0 & My \\
\hline
\end{tabular}

159, 165 and 167 did not show either motif 1 or 6 characteristic of the MADS domain. These proteins did contain other representative motifs of MADS-box family such as motifs 3, 4, 5, 7, 8, 9 and 10. The MIKC MADS-box proteins exhibited only the motif 1 type MADS domain.

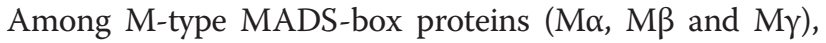
most $M \alpha$ and $M \gamma$ proteins had motif 1-type MADS domains, although BrMADS101 and 102 contained motif 6. Conversely, most of the $M \beta$ proteins (14) had the motif 6-type MADS domain.

Conserved motifs 2, 5 and 7 specified the $\mathrm{K}$ domain, which is characteristic of MIKC MADS-box proteins, were found in varying combinations in most $\mathrm{MIKC}^{\mathrm{C}}$ proteins, except BrMADS1, 84, 86 and 88. MIKC proteins 

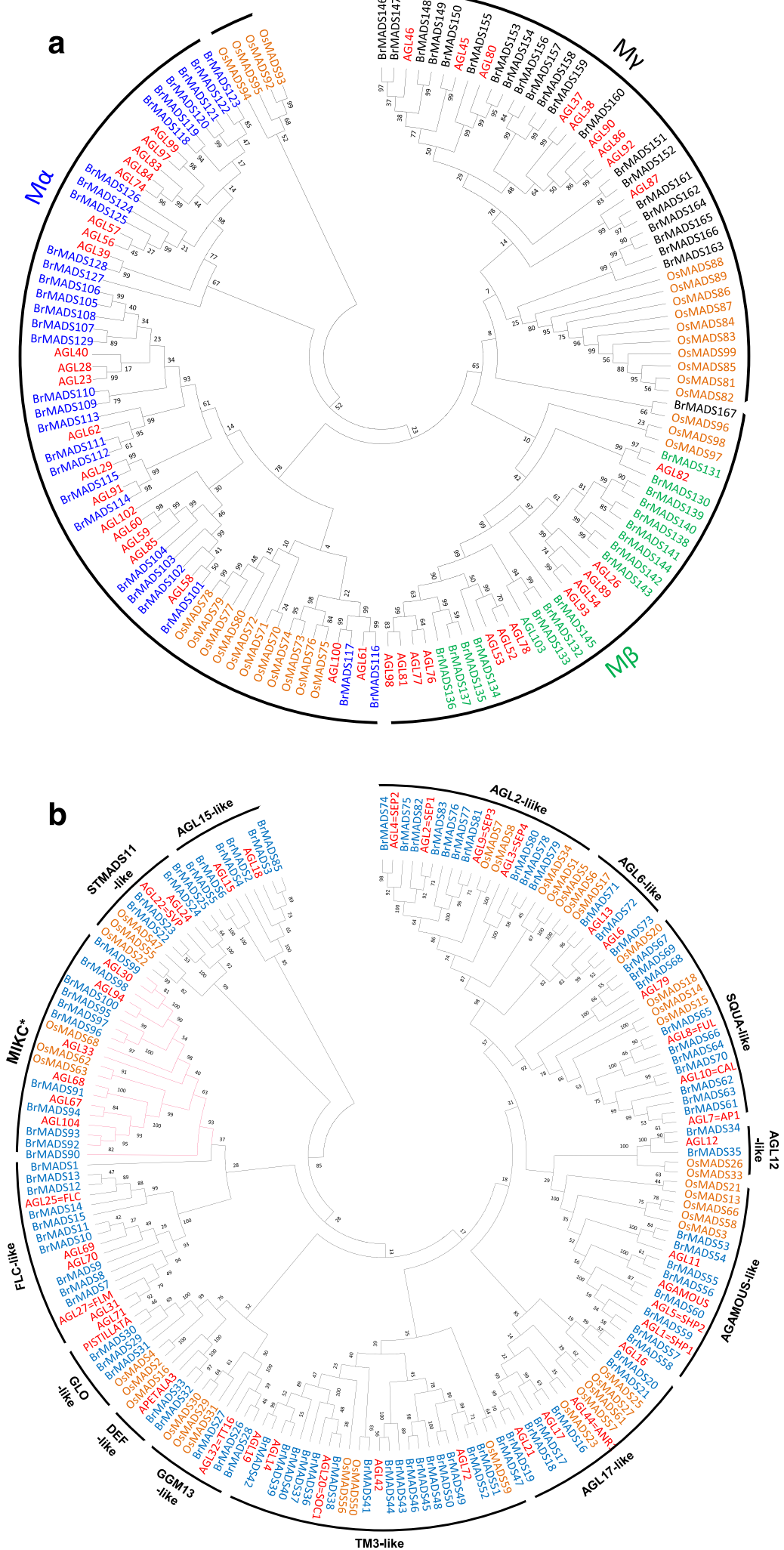

Figure 1 Phylogenetic tree constructed by the neighbor-joining method using MADS-box genes from B. rapa, Arabidopsis and Rice. (a) Phylogenetic analysis of 138 type I MADS-box proteins from B. rapa (67), Arabidopsis (43) and Rice (28). (b) Phylogenetic analysis of type II B. rapa, Rice and Arabidopsis MADS-box proteins. 181 type II MADS-box proteins from B. rapa (100), Arabidopsis (43) and rice (38) showing 13 MIKC ${ }^{\complement}$ clades and MIKC* group as marked in the figure. 


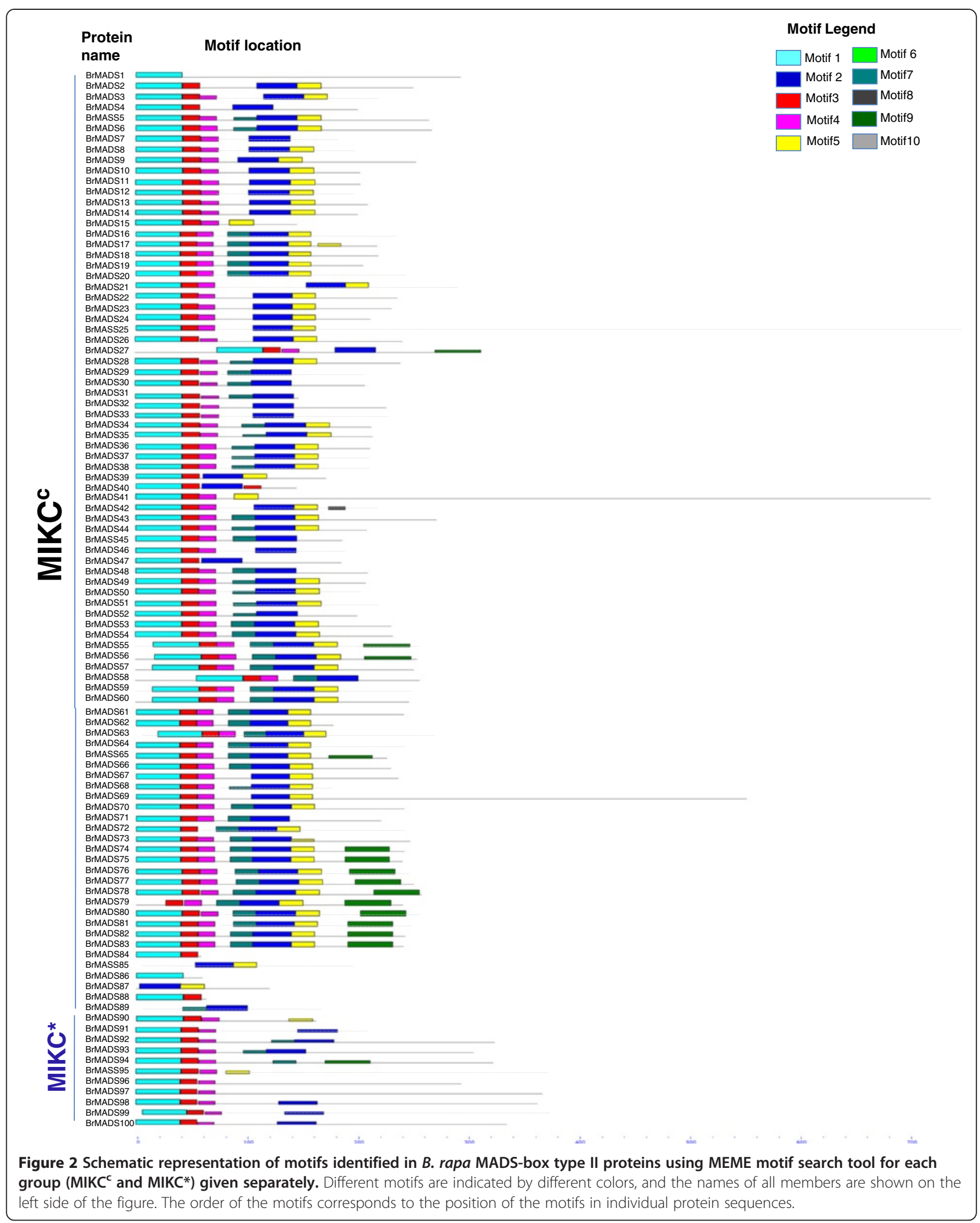




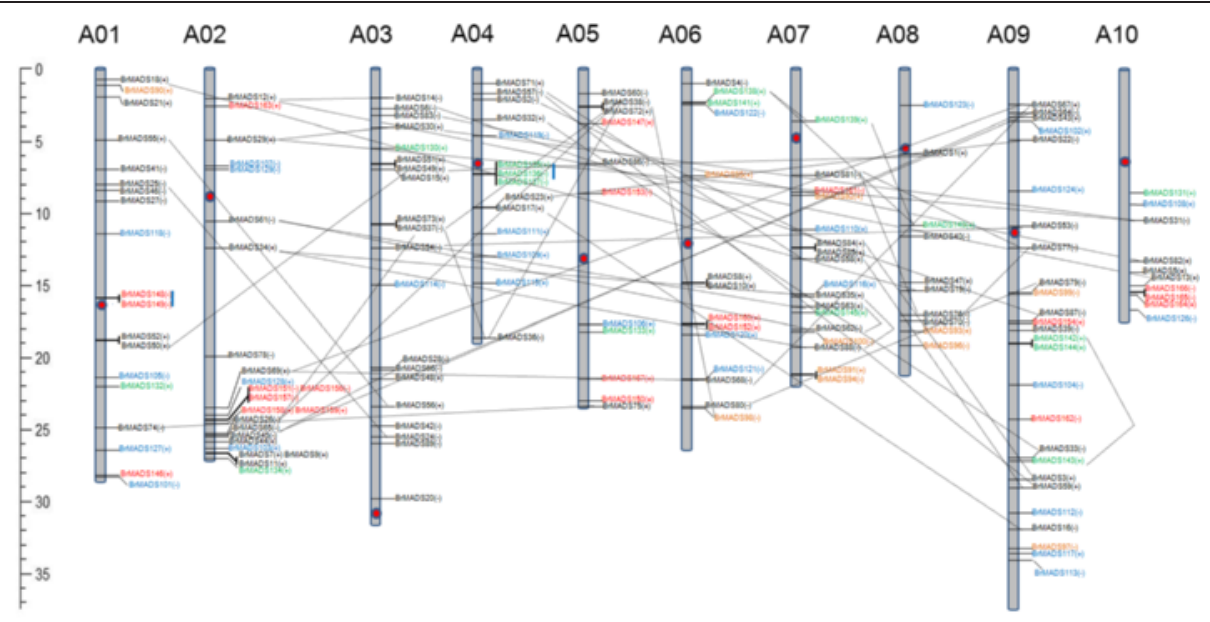

Figure 3 Chromosomal location of $\boldsymbol{B}$. rapa MADS-box genes along ten (10) chromosomes. Respective chromosome numbers are written as $\mathrm{A} 01$ to $\mathrm{A} 10$ on the top of each chromosome. Different colors of gene name represent different groups (black: MIKC ${ }^{\mathrm{C}}$, orange: MIKC*, blue: Ma, green: $M \beta$ and red: $M \gamma)$. The positive (+) and negative (-) signs following each gene represent forward and reverse orientation of the respective gene. Genes lying on duplicated segments of genome are joined by black dotted lines. Tandemly duplicated genes are shown by blue vertical blue lines. Gene position and each chromosome size can be estimated using the scale (in Megabase; Mb) on the left of the figure.

were found to contain the K-domain motifs $(2,5$, and 7$)$ less frequently than did MIKC ${ }^{\mathrm{C}}$ proteins (Figure 2). Comparatively less conserved motifs 3 and 4 representative of the I domain were found in both M-type and MIKC MADS-box proteins. $\mathrm{M} \beta$ and $\mathrm{M} \gamma$ type proteins contained I domains at lower frequencies as compared to members of the other groups. A considerable number of non-MIKC proteins, especially from the M $\alpha$ group, showed partial $\mathrm{K}$ domain motifs. Finally, motifs 8,9 and 10 representing the C-terminal domains were also weakly conserved among B. rapa MADS-box genes. Motif 9 was restricted to 14 $\mathrm{MIKC}^{\mathrm{C}}$ and $1 \mathrm{MIKC}^{* *}$ proteins. All My proteins except BrMADS161 and 162 consistently showed both the Cterminal-representing motifs 8 and 10 . Motif 8 and 10 were limited to only M-type MADS-box proteins. The $M \alpha$ group showed motif 8 , but motif 10 was exclusively present in the $\mathrm{M} \gamma$ proteins. The $\mathrm{M} \beta$ group showed an interesting pattern, wherein 7 genes contained only a single motif, specifically one representative of the 'MADS' domain. Only $4 \mathrm{M} \beta$ genes out of 16 had more than two full or partial motifs (Additional file 2: Figure S3).

\section{Syntenic relationships between MADS-box genes of B. rapa and Arabidopsis}

Polyploidy [arising from whole-genome duplication (WGD)] has played a vital role in the evolution and genetic diversity of angiosperm genomes [41]. WGD events are generally followed by changes in gene expression and widespread gene loss [42]. The Brassica genus is closely related to the model species $A$. thaliana and both are members of the Brassicaceae family. Comparative genetic and physical mapping as well as genome sequencing studies have authenticated the syntenic relationships between the Arabidopsis genome and the triplicate genome of B. rapa, with subgenomes having evolved by genome fractionation $[43,44]$. Comparative analysis was conducted to identify homologous MADS-box transcription factors between B. rapa and Arabidopsis. Based on our phylogenetic results and BLASTX reconfirmation, we determined which Arabidopsis MADS-box genes were orthologous to the 167 MADS-box B. rapa homologs. Among the homologous gene sets, we found that most Arabidopsis MADS-box genes were represented by one to three copies of B. rapa MADS-box genes (Additional file 1: Table S3).

\section{Chromosomal location of MADS-box genes and their genomic duplication in $B$. rapa}

We mapped the physical locations of the MADS-box genes on the 10 chromosomes of $B$. rapa (except two genes mapped to scaffolds Scaffold000343 and Scaffold000385; Figure 3). The highest numbers of MADS-box genes were found on chromosomes 9 (26 genes; 15.8\%) and 2 (24 genes; $14.5 \%$ ), while chromosomes 8 and 10 contained the fewest (10 each). Among the five types of MADS-box genes, MIKC* and $\mathrm{M} \gamma$ genes were clustered along chromosomes 1, 6, 7, 8, 9 and chromosomes 1, 2, 5, 6, 7, 9, 10, respectively. A high of $18 \mathrm{MIKC}^{\mathrm{C}}$ genes was found on chromosome 3, but other than that there was no bias was observed in the distribution of $\mathrm{MIKC}^{\mathrm{c}}, \mathrm{M} \alpha$ or $\mathrm{M} \beta$ genes (Figure 3). Duplication analysis revealed that 67 out of 167 MADS-box genes (40.12\%) were present in two or more copies. This gene duplication occurred as a result of tandem and segment duplications. A total of 63 MADS-box genes were found to have counterparts on duplicated segments. We observed, higher frequencies of segmental 


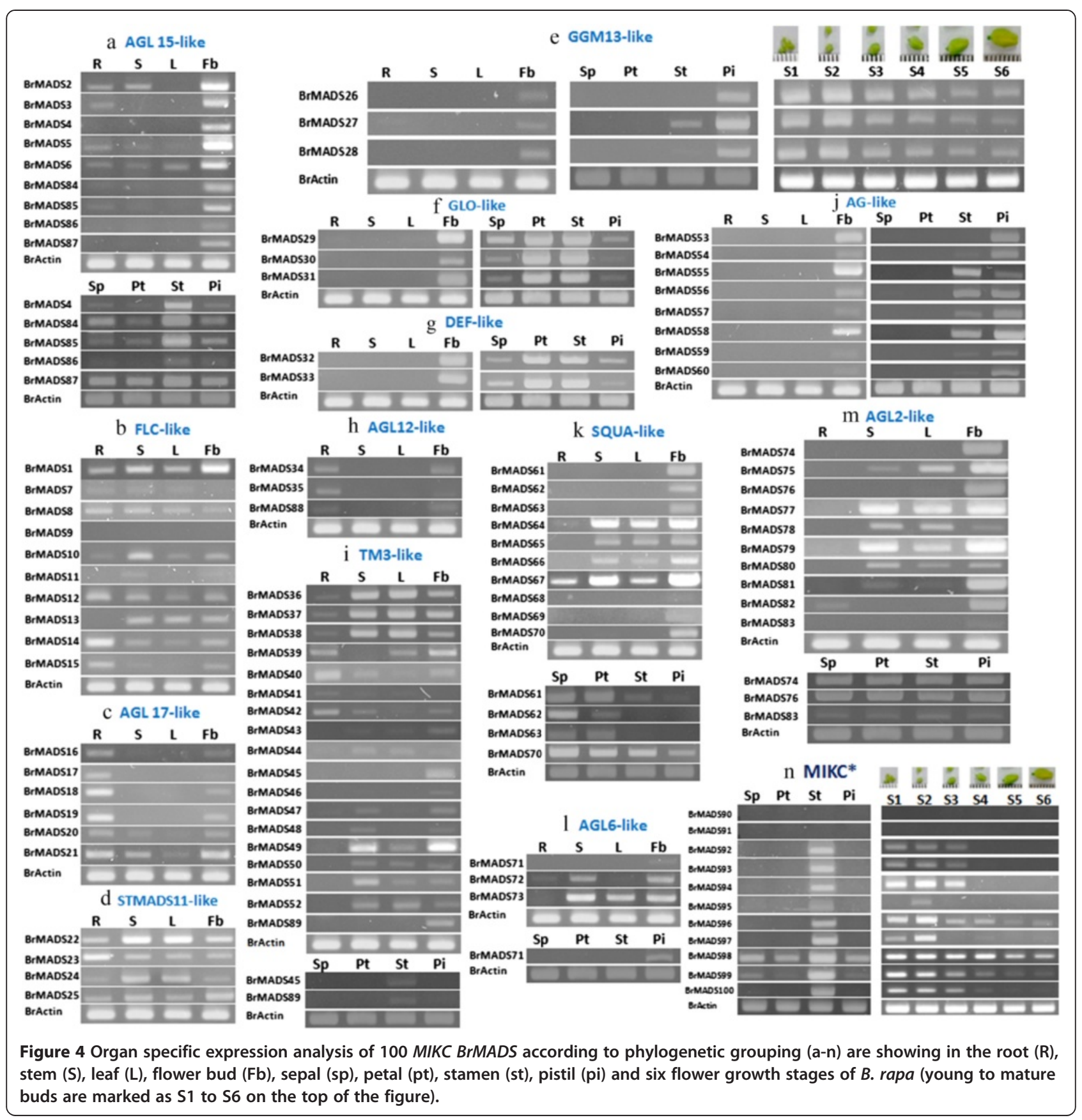

duplications generated many homologs of MADS-box genes along all chromosomes of $B$. rapa (black dotted lines in Figure 3). Conversely, lower frequencies of tandem duplications were evident among M-type B. rapa MADSbox genes. Only 4 tandemly duplicated genes (from $M \beta$ and $\mathrm{M} \gamma$ ) were found on chromosomes 1 and 4. Evolutionary analysis of $B$. rapa also validated our findings, wherein only $14 \%$ of the B. rapa genes were tandem duplicates, compared with $27 \%$ of Arabidopsis genes in a $100-\mathrm{kbp}$ window interval [45]. No large gene clusters or hot spots for B. rapa MADS-box genes were identified, possibly due to the very few tandem duplications.

Transcript analysis of $B$. rapa MADS-box genes during organ development

MADS-box genes have been found to be involved primarily in floral organ specification; although some recent studies revealed their involvement in other processes as well. Specifically, MIKC ${ }^{\mathrm{c}}$ proteins among all the MADSbox groups have been found to have diverse functions 
related to plant growth and development $[1,25,35,46]$. We therefore examined the expression of all $89 \mathrm{~B}$. rapa $M I K C^{\mathrm{C}}$ genes in root, stem, leaf and flower buds. We also investigated these genes in the sepal, petal, stamen and pistil of $B$. rapa flower which had expressions only in the flower buds. And, we discussed the expression of all $\mathrm{MIKC}^{\mathrm{C}}$ genes here in accord with thirteen clades identified in our study. Additionally, we included all MIKC* genes in the four floral tissue expression study as they have been reported to be involved in the development of reproductive organs [47]. Finally, we conducted an expression study in six flower bud developmental stages (young to mature bud stage) for selected MIKC $C^{\mathrm{C}}$ genes (those expressed only in flower buds) and all MIKC* genes to justify their roles during the flower bud development (Figure 4).

\section{AGL15-like genes}

It has been reported that AGL15 in Arabidopsis strongly delays abscission and senescence in reproductive tissues [9]. The $B$. rapa genome has nine AGL15-like genes (BrMADS2, 3, 4, 5, 6, 84, 85, 86, 87) and their expression in different tissues was consistent with that of their closest Arabidopsis homologs. All of the genes had predominant expression in flower buds while a few of them were expressed at low levels in different vegetative tissues (Figure 4a).

\section{FLC-like genes}

FLC acts as an inhibitor of flowering and is a convergence point for environmental and endogenous pathways that regulate flowering time in Arabidopsis [9]. We found ten FLC homologs [BRMADS1, 7, 8, 9, 10, 11 , and 15 in addition to the previously identified BrFLC1 (BrMADS12), BrFLC2 (BrMADS13), and BrFLC3 (BrMADS14)] in B. rapa with very similar expression patterns in most organs. BrMADS1 is a distant member of this subfamily and showed strong expression in the four tissues tested. Our root expression results for BrFLC1 and BrFLC2 contrast with those previously reported [40]. This might be due to varietal differences of B. rapa between the two studies. BrMADS9 is the only member of this subfamily that was not expressed in any of the organ tissues (Figure 4b).

\section{AGL17-like genes}

The AGL17-like genes show unusually diverse expression patterns, with members being expressed in roots (majority of genes), in pollen (DEFH125 in Antirrhi$n u m)$, in both (ZmMADS2 in maize), or in leaf guard cells and trichomes (AGL16) [9]. We identified six AGL17-like genes (BrMADS16, 17, 18, 19, 20, 21) and found expression primarily in roots of $B$. rapa like their Arabidopsis counterparts. Additionally, they were expressed in flower buds like in other eudicots [9]. We also observed low expression in stem and leaf tissues (Figure 4c).

\section{STMADS11-like genes}

Genes of this clade perform contrasting roles in flower development. SVP (SHORT VEGETATIVE PHASE) functions as a floral repressor, whereas AGL24 belongs to the same subfamily but promotes flowering in Arabidopsis $[48,49]$. We identified four genes (BrMADS22, 23, 24, $25)$ in this subfamily and detected their widespread expression in the four organs of $B$. rapa (Figure $4 \mathrm{~d}$ ). This is in contrast to the expression of SVP in Arabidopsis, which is restricted to leaves and shoots [9].

\section{GGM13-like genes}

The GGM13-like genes are expected to represent a sister group of the $\mathrm{B}$ genes and hence are termed $\mathrm{B}_{\text {sister }}\left(\mathrm{B}_{\mathrm{s}}\right)$ genes [9]. ABS/TT16 is the only Arabidopsis GGM13-like gene and has been shown to function in the specification of endothelial cells as well as in the control of flavonoid biosynthesis in the seed coat [23]. We identified three GGM13-like genes (BrMADS26, 27, 28), with expression exclusively in the flower buds like their Arabidopsis counterparts. All three were expressed in the female reproductive organ of $B$. rapa flowers, whereas $\operatorname{BrMADS} 27$ was also expressed in the male reproductive organ. Interestingly, transcript accumulation of all GGM13-like genes gradually decreased from early to mature bud stage of flower development (Figure 4e).

\section{GLO and DEF-like genes}

These genes are B class floral homeotic genes in eudicots and are involved in specifying petals and stamens during flower development [50]. We found three GLOlike genes (BrMADS29, 30,31) and two DEF-like genes (BrMADS32, 33) that were expressed exclusively in the flower buds. Transcripts for these genes were abundant in the petals and stamens of $B$. rapa flowers. We also found low expression in sepals and pistils (Figure $4 \mathrm{f} \mathrm{\&} \mathrm{4g).}$

\section{AGL12-like genes}

Three AGL12-like genes (BrMADS34, 35, 88) with preferential expression in roots were detected in $B$. rapa. BrMADS34 and 88 were also expressed in the flower buds, similar to their Arabidopsis counterpart AGL12 with the exception that $A G L 12$ has also been detected in shoots (Figure 4h).

\section{TM3-like genes}

These genes are expressed preferentially in vegetative parts of other plant species [51,52]. SOC1 is an important member of this family expressed abundantly in the apical meristem and acting as a flowering time regulator [53]. We identified eighteen TM3-like genes (BrMADS36, 37, 
$38,39,40,41,42,43,44,45,46,47,48,49,50,51,52$ and 89 ) with variable expression patterns in vegetative and reproductive parts of $B$. rapa. BrMADS36, 37 and 38 are close homologs of SOC1 and were primarily expressed in stem, leaf and flower buds. Moreover, we found BrMADS39, 40 and 42 to be expressed primarily in roots, but unlike their Arabidopsis counterparts (AGL14 and AGL19), we detected their expression in other parts of the plant as well (Figure 4i).

\section{AG-like genes}

Genes of this clade are mainly involved in specifying stamen and carpel identity, and in providing floral determinacy [9]. We identified eight AGAMOUS-like (AG) genes (BrMADS53, 54, 55, 56, 57, 58, 59, 60) that were expressed exclusively in flower buds of $B$. rapa. Our results are consistent with those for the Arabidopsis $A G$ subfamily, members of which specify stamen and carpel identity [54]. Some of these $B$. rapa genes were pistil specific (BrMADS53 and 54) and some were expressed in both male and female reproductive organs (BrMADS55, 56, 57, 58, 59 and 60) (Figure 4j).

\section{SQUA-like genes}

SQUA-like genes are typically expressed in inflorescence or floral meristems, and most of them function as meristem identity genes [9]. In addition, they are involved in specifying sepals and petals and thus are class 'A' floral organ identity genes [55]. We identified ten SQUA-like genes (BrMADS61, 62, 63, 64, 65, 66, 67, 68, 69, 70) that had variable transcript patterns, but were expressed mainly in flower buds like their Arabidopsis counterparts. Some BrMADS SQUA-like genes showed strong expression in the stem and leaf as well. Our results in this case are also consistent with the $\mathrm{Gu}$ et al. findings, where they detected the SQUA-like gene 'FRUITFULL' in stems and leaves of Arabidopsis [21]. BrMADS67 was the only member of this subfamily expressed in all tested organ tissues of B. rapa (Figure 4k).

\section{AGL6-like genes}

The functions of AGL6-like genes are not clear. We isolated three AGL6-like genes (BrMADS71, 72, 73) from $B$. rapa with expression in the flower buds, like their Arabidopsis counterparts AGL6 and AGL13. BrMADS72 and 73 , unlike their close homolog $A G L 6$, also showed expression in vegetative tissues (Figure 4l).

\section{AGL2-like genes}

These genes play a central role in the floral meristem and floral organ development [56]. They constitute an additional class of floral homeotic genes, termed as class E genes [9]. Ten AGL2-like (BrMADS74, 75, 76, 77, 78, $79,80,81,82,83)$ genes from $B$. rapa showed expression primarily in reproductive tissues. $\operatorname{BrMADS75,} 77,78,79$, 80 and 81 were also expressed in the stem and leaf, and BrMADS82 alone had additional very low expression in roots (Figure $4 \mathrm{~m}$ ).

\section{BrMIKC* genes}

There were eleven MIKC* genes (BrMADS90, 91, 92, 93, $94,95,96,97,98,99,100)$ that were placed apart from the other MIKC genes in the phylogeny. Most of these genes were found to be expressed exclusively in the stamens, except in the case of BrMADS98 and 99, that were detected in the four floral organ tissues. Moreover, these genes showed differential expression in six flower bud developmental stages (young to mature bud stage). BrMADS96, 98, 99 and 100 were preferentially expressed in the young bud stage while their expression gradually decreased until to the mature bud stage. The rest of the genes exhibited widespread expression mainly in the early stages of bud development. However, two MIKC* genes (BrMADS90 and 91) appeared to be nonfunctional, as they were not expressed in any stage of bud development or in any floral organ tissues (Figure 4n).

\section{Microarray expression against cold and freezing stress}

Four weeks old seedlings of two inbred lines of B. rapa, Chiifu and Kenshin, were treated with cold and freezing stresses $\left(4^{\circ} \mathrm{C}, 0^{\circ} \mathrm{C},-2^{\circ} \mathrm{C}\right.$ and $\left.-4^{\circ} \mathrm{C}\right)$ during 2 hours and the expression of the 167 MADS-box genes were subsequently analyzed using microarrays. Chiifu originated in temperate regions, whereas Kenshin originated in subtropical and tropical regions and therefore, these two lines are expected to respond differently against cold and freezing stresses. Only 19 MADS-box genes from different groups showed differential cold- or freezing-responsive expression between the two lines (Figure 5), while the remaining 148 genes showed very low or no expression (Additional file 2: Figure S4). Among the 19 differentially expressed genes, $14 \mathrm{MIKC}^{\mathrm{C}}$ genes showed varying levels of expression, with BrMADS7, 10, 24 and 39 displaying similar expression patterns in response to cold and freezing. BrMADS11, 12, 14, 20, 23, 36, 38 and 40 were expressed at different levels than the aforementioned four $\mathrm{MIKC}^{\mathrm{C}}$ genes in both lines of B. rapa. BrMADS43 and 44, two MIKC $C^{\mathrm{C}}$ genes, were expressed at low levels in Chiifu throughout the stress period, while in Kenshin they showed constitutive expression. By contrast, three genes from the M $\alpha$ group (BrMADS103, 109 and 127) showed differential expression within and between the two lines, with Chiifu exhibiting higher expression than Kenshin. Notably, two $\mathrm{M} \gamma$ genes (BrMADS146 and BrMADS155) showed higher responsiveness in Kenshin than in Chiifu upon exposure to cold and freezing temperatures (Figure 5). 


\begin{tabular}{|c|c|c|c|c|c|c|c|c|c|c|c|c|c|}
\hline & Gene name & C1 & $\mathrm{C} 2$ & $\mathrm{C} 3$ & $\mathrm{C4}$ & C5 & K1 & K2 & K3 & K4 & \multicolumn{3}{|c|}{ K5 } \\
\hline & BrMADS7 & $4245^{t}$ & $4.273^{\circ}$ & $4.176^{\circ}$ & $4.176^{4}$ & $4.674^{\circ}$ & $5.699^{\circ}$ & $5.084^{4}$ & $4.886^{\circ}$ & $5,488^{2}$ & \multicolumn{3}{|c|}{$5.557^{\circ}$} \\
\hline & & $1.00^{\circ}$ & $1.21^{\circ}$ & $1.73^{\circ}$ & $1.80^{\circ}$ & $1.65^{\circ}$ & $1.00^{\circ}$ & $0.99^{\circ}$ & $1.06^{\circ}$ & $0.96^{\circ}$ & \multicolumn{3}{|c|}{$2.11^{\circ}$} \\
\hline & BrMADS10 & $7328^{4}$ & $6,100^{4}$ & $7.936^{\circ}$ & $6.152^{2}$ & $7956^{\circ}$ & $6.576^{\circ}$ & $5,464^{4}$ & $4.843^{\circ}$ & $6.271^{\circ}$ & \multicolumn{3}{|c|}{$6.205^{\circ}$} \\
\hline & & $1.00^{d}$ & $1.23^{\mathrm{es}}$ & $1.30^{\circ}$ & $1.89^{\circ}$ & $4.29^{\circ}$ & $1.00^{4}$ & $1.95^{\circ}$ & $1.40^{\circ}$ & $2.00^{\circ}$ & \multicolumn{3}{|c|}{$7.78^{\circ}$} \\
\hline & BrMADS11 & $5,795^{\circ}$ & $6,448^{2}$ & $5,728^{\circ}$ & $7,153^{\circ}$ & $7363^{\circ}$ & $3,319^{t}$ & $3.281^{\circ}$ & $4.767^{\circ}$ & $4.208^{2}$ & \multicolumn{3}{|c|}{$2,995^{\circ}$} \\
\hline & & $1.00 b^{2}$ & $0.86^{\circ}$ & $1.25^{\circ}$ & $1.21^{\circ}$ & $2.87^{\circ}$ & $1.00^{\circ}$ & $0.95^{\circ}$ & $0.88^{\circ}$ & $2.38^{\circ}$ & \multicolumn{3}{|c|}{$1.49^{\circ}$} \\
\hline & BrMADS12 & $4.221^{\circ}$ & $3,763^{\circ}$ & $4,487^{\circ}$ & $3,772^{4}$ & $4.169^{t}$ & $3,826^{\circ}$ & $3.285^{\circ}$ & $3,398^{\mathrm{t}}$ & $3.216^{\circ}$ & \multicolumn{3}{|c|}{$\begin{array}{c}1.49^{\circ} \\
3.575^{\circ}\end{array}$} \\
\hline & & $1.00^{\circ}$ & $1.00^{\circ}$ & $0.96^{\circ}$ & $1.61^{\circ}$ & $2.19^{\circ}$ & $1.00^{\mathrm{es}}$ & $1.37^{\circ}$ & $0.76^{d}$ & $1.09^{\circ}$ & & $2.61^{\circ}$ & \\
\hline & BrMADS14 & $3,149^{t}$ & $4.025^{\circ}$ & $3,140^{4}$ & $3.294^{\circ}$ & $2.367^{\circ}$ & $4.678^{t}$ & $4,724^{\circ}$ & $3,798^{\circ}$ & $5,677^{*}$ & & $4,448^{4}$ & \\
\hline & & $1.00^{\circ}$ & $1.13^{\circ}$ & $1.02^{2}$ & $1.53^{\circ}$ & $1.95^{\circ}$ & $1.00^{\circ}$ & $1.05^{\circ}$ & $0.66^{\circ}$ & $0.89 b^{2}$ & & $2.40^{*}$ & \\
\hline & BrMADS20 & $2.503^{\circ}$ & $3,704^{\circ}$ & $4.864^{*}$ & $3.536^{\circ}$ & $2, A 60^{\circ}$ & $1,699^{\circ}$ & $3.209^{4}$ & $3.247^{\circ}$ & $2,719^{4}$ & & $3,313^{\circ}$ & \\
\hline & & $1.00^{d}$ & $1.26^{\mathrm{es}}$ & $1.50^{\circ}$ & $2.59^{\circ}$ & $3.53^{\circ}$ & $1.00^{\circ}$ & $2.43^{=}$ & $1.40^{d}$ & $2.85^{\circ}$ & & $6.00^{*}$ & \\
\hline & BrMADS23 & $1.502^{\circ}$ & $2.597^{\circ}$ & $2,497^{\circ}$ & $2,180^{\circ}$ & $2,309^{4}$ & $3,149^{6}$ & $2.566^{4}$ & $4.162^{\circ}$ & $2,299^{\circ}$ & & $4,787^{\circ}$ & \\
\hline$\underline{=}$ & & $1.00^{\circ}$ & $1.29^{\circ}$ & $1.31^{\circ}$ & $1.55^{\circ}$ & $1.55^{\circ}$ & $1.00^{\circ}$ & $1.44^{\circ}$ & $1.02^{\mathrm{s}}$ & $1.32^{\mathrm{b}}$ & & $3.84^{\circ}$ & \\
\hline$\Sigma$ & BrMADS24 & $4.188^{\circ}$ & $4,456^{\circ}$ & $4.311^{t}$ & $3.881^{\circ}$ & $5.337^{\circ}$ & $5.396^{2}$ & $5.275^{4}$ & $5.360^{t}$ & $4.969^{\circ}$ & & $5.958^{\circ}$ & \\
\hline & & $1.00^{\circ}$ & $1.06^{=}$ & $0.85^{\circ}$ & $1.60^{\circ}$ & $3.59^{\circ}$ & $1.00^{\circ}$ & $3.22^{\mathrm{b}}$ & $2.08^{\circ}$ & $2.62^{\mathrm{s}}$ & & $5.94^{\circ}$ & \\
\hline & BrMADS36 & $3,738^{2}$ & $4.680^{\circ}$ & $4.535^{1}$ & $2.580^{\circ}$ & $2.950^{4}$ & $4.854^{\circ}$ & $3,696^{\circ}$ & $4,043^{\prime}$ & $4,760^{\circ}$ & & $3.917^{\circ}$ & \\
\hline & & 1.00 & $0.63^{b}$ & $0.77^{\star}$ & $0.93^{\circ}$ & $0.63^{\circ}$ & $1.00^{*}$ & $0.77^{\mathrm{te}}$ & $0.29^{\circ}$ & $0.57^{\circ}$ & & $1.24^{*}$ & \\
\hline & BrMADS38 & $2,162^{4}$ & $2.732^{\circ}$ & $2,326^{6}$ & $2, A 36^{\circ}$ & $1,180^{\circ}$ & $3.572^{\circ}$ & $2.915^{\circ}$ & $3.538^{t}$ & $4,266^{\circ}$ & & $2.980^{\circ}$ & \\
\hline & & $1.00^{\circ}$ & $0.98^{b}$ & $0.73^{\circ}$ & $1.44^{\circ}$ & $0.80^{\circ}$ & $1.00^{\circ}$ & $0.86^{\circ}$ & $0.29^{d}$ & $0.57^{\circ}$ & & $1.31^{\circ}$ & \\
\hline & BrMADS39 & $6,166^{t}$ & $6.553^{\circ}$ & $6.299^{\circ}$ & $5.901^{4}$ & $5,653^{\circ}$ & $6,786^{\circ}$ & $7.006^{\circ}$ & $8.328^{2}$ & $B, A 28^{\circ}$ & & $7,604^{5}$ & \\
\hline & & $1.00^{\circ}$ & $1.01 \%$ & $0.98^{\circ}$ & $2.21^{\circ}$ & $3.84^{\circ}$ & $1.00^{a}$ & $1.84^{\circ}$ & $1.13^{\mathrm{e}}$ & $1.79^{\circ}$ & & $4.26^{*}$ & \\
\hline & BrMADS 40 & $3,878^{\circ}$ & $3,983^{\circ}$ & $3,814^{\circ}$ & $3.285^{4}$ & $3.329^{6}$ & $3,987^{4}$ & $4,447^{*}$ & $4.174^{2}$ & $3.884^{\circ}$ & & $4.287^{\circ}$ & \\
\hline & & $1.00^{\circ}$ & $1.21^{\circ}$ & $1.12^{z}$ & $2.13^{\circ}$ & $3.71^{\circ}$ & $1.00^{\circ}$ & $2.43^{b}$ & $1.32^{d}$ & $1.91^{\circ}$ & & $4.58^{\circ}$ & \\
\hline & BrMADS43 & $1,173^{\circ}$ & $319^{4}$ & $909^{\circ}$ & $211^{\circ}$ & $196^{4}$ & $2,027^{2}$ & $2.633^{\circ}$ & $2.998^{\circ}$ & $1,402^{\circ}$ & & $1,758^{\circ}$ & \\
\hline & & $1.00^{d}$ & $1.54^{\circ}$ & $1.08^{d}$ & $2.47^{\circ}$ & $4.22^{\circ}$ & $1.00^{\circ}$ & $1.27^{\circ}$ & $0.51=$ & $0.90^{\circ}$ & & $0.93^{\circ}$ & \\
\hline & BrMADS44 & $583^{\circ}$ & $461^{\circ}$ & $718^{\circ}$ & $435^{\circ}$ & $641^{\circ}$ & $2,306^{t}$ & $2 A 87^{\circ}$ & $2 A 71^{\circ}$ & $2,609^{\circ}$ & & $2.211^{4}$ & \\
\hline & & $1.00^{d}$ & $2.11^{\mathrm{s}}$ & $1.91 \mathrm{~s}$ & $2.63^{\circ}$ & $4.61^{\circ}$ & $1.00^{\circ}$ & $1.41^{\circ}$ & $0.71 \mathrm{a}$ & $1.19 *$ & & $1.42^{*}$ & \\
\hline & BrMADS103 & $8.016^{\circ}$ & $3.165^{t}$ & $3,158^{t}$ & $2.352^{4}$ & $4,495^{\circ}$ & $5.286^{\circ}$ & $4.278^{8}$ & $3.802^{\circ}$ & $2,028^{\circ}$ & & $4.232^{6}$ & \\
\hline & & $1.00^{\circ}$ & $0.52^{\mathrm{a}}$ & $0.61^{\mathrm{e}}$ & $0.93^{\circ}$ & $2.07^{\circ}$ & $1.00^{d}$ & $1.91^{\circ}$ & $1.70^{\circ}$ & $1.41^{\circ}$ & & $5.13^{\circ}$ & \\
\hline$\Sigma$ & BrMADS109 & $6,100^{t}$ & $9.286^{*}$ & $8.351^{\circ}$ & $4.522^{\circ}$ & $5.697^{4}$ & $243^{\circ}$ & $115^{4}$ & $384^{2}$ & $848^{*}$ & & $126^{\circ}$ & \\
\hline & & $1.00^{4}$ & $1.44^{*}$ & $1.37^{=}$ & $2.40^{\circ}$ & $4.15^{\circ}$ & $1.00^{\mathrm{te}}$ & $1.48^{\circ}$ & $0.85^{\circ}$ & $1.13^{\circ}$ & & $1.611^{\circ}$ & \\
\hline & $\mathrm{I}_{\text {BrMADS127 }}$ & $1.003^{\circ}$ & $2.039^{4}$ & $2.032^{t}$ & $3,106^{*}$ & $2,157^{\circ}$ & $830^{\circ}$ & $1.060^{t}$ & $978^{4}$ & $1,338^{\circ}$ & & $1,141^{\circ}$ & \\
\hline & & $1.00^{\circ}$ & $2.16^{\circ}$ & $2.09^{\circ}$ & $3.07^{\circ}$ & $2.97^{\circ}$ & $1.00^{4}$ & $2.77^{\circ}$ & $1.08^{\circ}$ & $1.92^{\mathrm{s}}$ & & $4.08^{\circ}$ & \\
\hline & BrMADS146 & $299^{\circ}$ & $304^{4}$ & $482^{\circ}$ & $522^{\circ}$ & $437^{\circ}$ & $1,163^{\circ}$ & $4.797^{\circ}$ & $4.534^{5}$ & $6.838^{\circ}$ & & $3.237^{\circ}$ & \\
\hline z & & $1.00^{\circ}$ & $4.05^{d}$ & $5.35^{\circ}$ & $37.26^{\circ}$ & $15.02^{\mathrm{b}}$ & $1.00^{\circ}$ & $38.50^{\circ}$ & $24.81^{\circ}$ & $29.14^{*}$ & & $9.51^{\circ}$ & \\
\hline & $=I_{\text {BrMADS155 }}$ & $212^{\circ}$ & $770^{\circ}$ & $2,928^{\circ}$ & $3.247^{\circ}$ & $330^{\circ}$ & $225^{\circ}$ & $2.802^{4}$ & $3.874^{6}$ & $8,716^{*}$ & & $5.319^{\circ}$ & \\
\hline & & $1.00^{4}$ & $1.57^{\mathrm{E}}$ & $2.95^{\circ}$ & $8.07^{\circ}$ & $2.90^{\circ}$ & $1.00^{\circ}$ & $21.97^{\circ}$ & $19.61^{d}$ & $44.64^{\circ}$ & & $3.84^{\circ}$ & \\
\hline & Legend: & 20,000 & 4,00 & 999 & $8,000-13,999$ & $4,000-7,999$ & $2,000-3999$ & & 999 & $500-999$ & $200-499$ & & 99 \\
\hline $\begin{array}{l}\text { Figur } \\
\text { unde } \\
\text { and 'k } \\
\text { show }\end{array}$ & $\begin{array}{l}\text { ure } 5 \text { Microarray } \\
\text { er control }(\mathbf{C} 1 \& \mathbf{K} \\
\text { 'kenshin' two inbr } \\
\text { Nn on the left side } \\
\text { ificantly at } P<0.05\end{array}$ & $\begin{array}{l}\text { upper co } \\
4^{\circ} \mathrm{C}(\mathrm{C} 2 \\
\text { d lines of } \\
\text { Color bar } \\
\text { according }\end{array}$ & $\begin{array}{l}\text { d row } \\
\text { ), } 0^{\circ} \mathrm{C} \\
\text { apa re } \\
\text { the ba }\end{array}$ & $\begin{array}{l}\text { d qPCR } \\
\text { K3), -2 } \\
\text { vely. Re } \\
\text { resentir } \\
\text { ultiple }\end{array}$ & $\begin{array}{l}\text { pression } \\
\text { C4\&K4), } \\
\text { nsive ge } \\
\text { differenti } \\
\text { ye tests. }\end{array}$ & $\begin{array}{l}\text { ver grey col } \\
-4^{\circ} \mathrm{C}(\mathrm{C} 5 \& \mathrm{~K} \\
\text { in different te } \\
\text { pression in } \mathrm{n}\end{array}$ & $\begin{array}{l}\text { lored rows) } \\
\text { K5) temperat } \\
\text { temperature fr } \\
\text { microarray. Val }\end{array}$ & $\begin{array}{l}\text { again } \\
\text { ture } t \\
\text { from } \\
\text { alues }\end{array}$ & $\begin{array}{l}\text { ents. } H \\
\text { ed by th }\end{array}$ & $\begin{array}{l}\text { IADS-box } \\
\text { ere C and } \\
\text { 5-box grou } \\
\text { e same le }\end{array}$ & $\begin{array}{l}\text { nes in } \\
\text { tand } f \\
\text { have }\end{array}$ & $\begin{array}{l}\text { in } B \\
\text { for } \\
\text { be }\end{array}$ & \\
\hline
\end{tabular}

qPCR expression of MADS-box genes against abiotic stress One of our main objectives was to identify MADS-box genes that might show stress responsiveness in addition to having different growth functions. At first, a qPCR experiment was conducted to validate the cold and freezing responsiveness of the $19 \mathrm{BrMADS}$ genes which were selected from the microarray analysis. We observed their expression patterns and found them consistent with the microarray results in most of the cases. Only two genes (BrMADS43 and 44) were found to show their expressions differently from those in the microarray experiment (Figure 5). However, for a better understanding of gene expression in response to three abiotic stresses (cold, salt and drought) in a time course basis $(0 \mathrm{~h}$, $30 \mathrm{~min}, 1 \mathrm{~h}, 4 \mathrm{~h}, 8 \mathrm{~h}, 12 \mathrm{~h}, 24 \mathrm{~h}$ and $48 \mathrm{~h}$ ) we again selected two inbred lines of $B$. rapa, Chiifu and Kenshin. Leaf and root tissues of stress treated $B$. rapa were examined for qPCR expression analysis. Besides cold stress, we also examined the salt and drought responsiveness of the same MADS-box genes. Arora et al. found MADS-box genes involved in responses to multiple stresses [35]. The 19 differentially expressed MADS-box genes from the whole-genome low temperature-treated data set were selected for qPCR experiments (Additional 


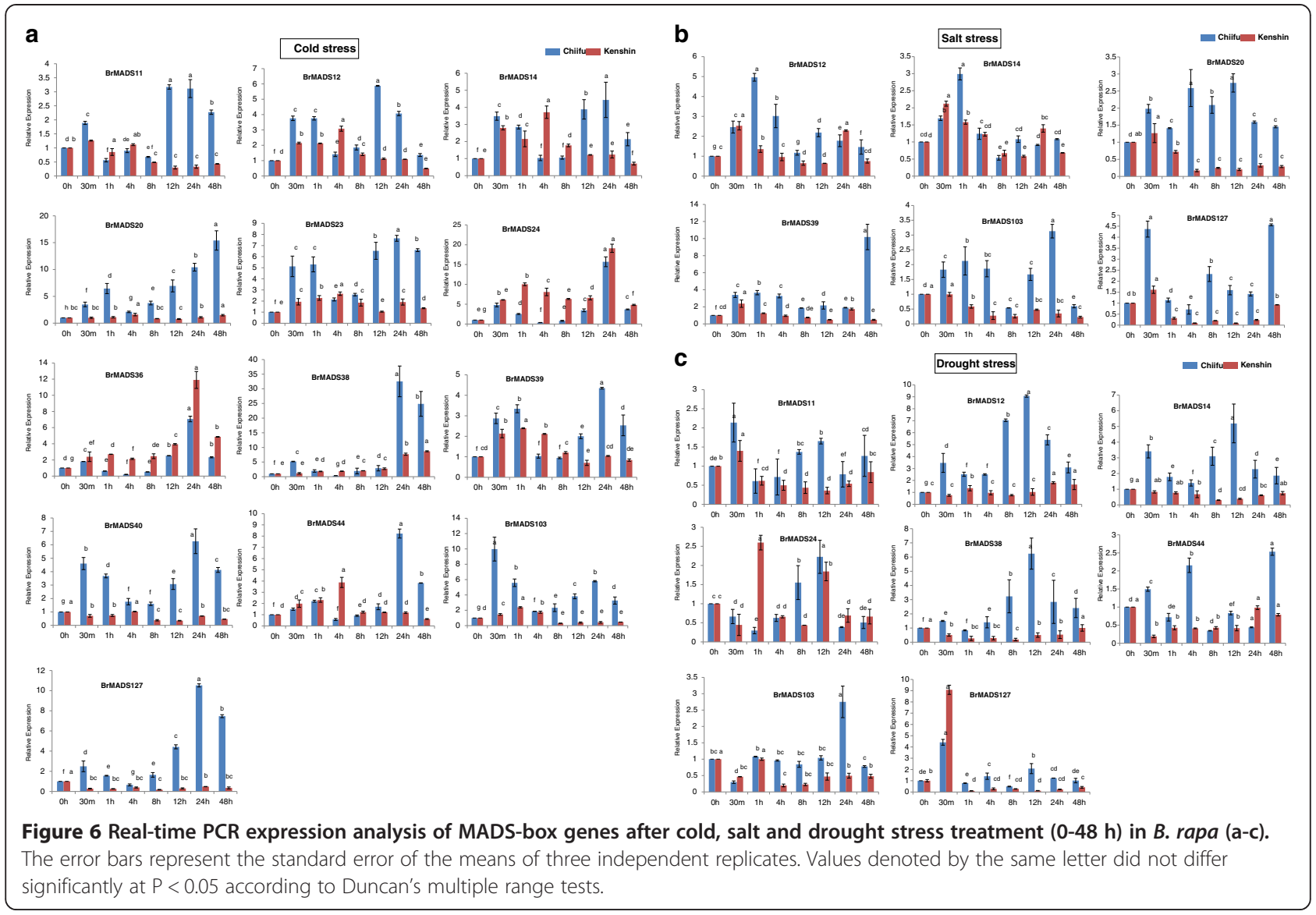

file 2: Figure S4 and Figure 5). In Chiifu, BrMADS11, 12, $14,20,23,24,36,38,3940,44,103$ and 127 showed differential expression in response to cold stress, wherein they were up-regulated from $0 \mathrm{~h}$ to $1 \mathrm{~h}$ and down-regulated at 4 h-8 h. Subsequently, all genes were up-regulated from $8 \mathrm{~h}$ to $24 \mathrm{~h}$ and exhibited their highest expression at $24 \mathrm{~h}$ (except BrMADS20, which showed the highest expression at $48 \mathrm{~h}$ ), followed by a down-regulation at $48 \mathrm{~h}$. Apart from these, BrMADS103 showed the highest expression at $30 \mathrm{~m}$, after which it followed the same expression patterns as the others. Conversely, in Kenshin, BrMADS11, 12, 14, 23, 39, 44 and 103 were up- regulated at early hours of stress after which they showed down-regulation and eventually became inactive at later stages of cold stress. BrMADS24, and 36 in Kenshin exhibited 19- and 12-fold higher expression respectively than the control throughout the stress period and, more interestingly, expression of these two genes in Chiifu was far below that in Kenshin. Notably, from the thirteen cold responsive BrMADS genes eleven were form MIKC group. More specifically, among these genes, three (BrMADS11, 12 and 14) were from FLC-like clade, one (BrMADS20) from AGL17-like clade, two (BrMADS23 and 24) from STMADS-like clade and five (BrMADS36, 38, 39, 40 and 44) from TM3-like clade (Figure 6a).
During salt stress, BrMADS12, 14, 39, 103 and 127 in Chiifu were up-regulated up to $1 \mathrm{~h}$, showed down-regulation in the mid-stage of stress and were up-regulated again at later stages. BrMADS2O was alternatively up and downregulated up to $12 \mathrm{~h}$ and afterwards it showed downregulation from $24 \mathrm{~h}-48 \mathrm{~h}$. In Kenshin, these same six MADS-box genes were induced early in salt treatment (up to a maximum of 2-fold in BrMADS12 and 39) and down-regulated for the rest of the period (Figure 6b).

In the case of drought stress, BrMADS11, 12, 14, 24, 38, 44, 103 and 127 were expressed differentially in both Chiifu and Kenshin. Six genes (BrMADS11, 12, 14, 38, 44 and 127) in Chiifu were up-regulated at $30 \mathrm{~m}$ after administering drought stress, while BrMADS11, 12, 14 and 38 were down-regulated from $4 \mathrm{~h}-8 \mathrm{~h}$. BrMADS24 and 103 were down-regulated at early stage, after which $B r M A D S 24$ was up-regulated from $4 \mathrm{~h}-12 \mathrm{~h}$ and downregulated again from $24 \mathrm{~h}-48 \mathrm{~h}$. After $30 \mathrm{~m}, \mathrm{BrMADS103}$ remained static except at $24 \mathrm{~h}$ when it was induced more than 2 fold. By contrast, these six MADS-box genes in Kenshin were down-regulated soon after drought treatment and remained that way throughout the stress period. Though BrMADS11, 24 and 127 showed up-regulation at an early stage, they eventually became inactive for the rest of the period (Figure 6c). 


\section{Discussion}

Duplication among MIKC genes seems to have played major role in the expansion of MADS-box genes in B. rapa

In this study, we have reported 167 MADS-box genes of $B$. rapa, which is higher in number than the MADS-box genes in Arabidopsis (107) [4]. The whole genome of $B$. rapa underwent triplication events since its divergence from Arabidopsis [32]. Thus, evolutionary relationship between $B$. rapa and Arabidopsis is also supportive to our findings. On the other hand, we observed the expansion of MIKC and M-type genes in these two linages. We found some disparity on the duplication events between the MIKC and M-type genes of $B$. rapa and Arabidopsis. For example, duplication events took place with higher frequency among MIKC-type $B$. rapa MADS-box genes compared to M-type genes. And, in case of Arabidopsis this scenario was reverse, where more number of M-type genes than MIKC genes was found in the duplicated segments. More specifically, 57 MIKC genes were found in duplicated segments of $B$. rapa (black dotted lines in Figure 3). This might be related to the fact that there are more pseudogenes of M-type than of MIKC-type MADSbox genes in the Arabidopsis genome and they experienced faster birth and death rates than MIKC type [57]. Although the B. rapa genome is triplicated relative to that of Arabidopsis, the number of M-type genes in $B$. rapa is almost the same as in Arabidopsis (Additional file 1: Table S1). We speculate this might be due to the presence of many non-functional M-type genes (i.e., psuedogenes) that remained inactive and were not duplicated or were deleted from the B. rapa genome. MIKC-type genes have functioned in growth and development of plants since their evolution and after multiple duplication events in B. rapa, MIKC-type genes appear to have functionally differentiated in a relatively short time and been maintained as functional genes in the genome to perform more complex functions flower and organ development.

\section{Involvement of MADS-box genes in organ development of $B$. rapa \\ Role in reproductive organ development}

Investigations regarding the genetic and molecular basis of floral development in the model eudicots Arabidopsis and Antirrhinum have revealed the involvement of a number of MADS-box genes in specifying floral organ identity [58]. The high degree of sequence identity and remarkably conserved genome structure between Arabidopsis and Brassica genomes enables comparison of crop genomics among the Brassica complex [45]. In this study, we investigated the Arabidopsis MADS-box homologs in $B$. rapa that play specific roles in flower development.
Consideration of the ABCDE model of flower development in $B$. rapa revealed extensive similarities with that of Arabidopsis and other higher plants.

All SQUA-like genes in B. rapa were typically expressed in the flower buds like their Arabidopsis counterparts. AP1 is involved in specifying sepals and petals as class A floral organ identity gene [53]. Our results also suggest that BrMADS61, 62, and 63 as putative orthologs of AP1 might play similar role, and they have sepal- and petalspecific expression in B. rapa flowers (Figure 4k).

Regarding the $\mathrm{B}$ class genes in $B$. rapa, we found five close homologs of Arabidopsis PISTILLATA (PI) and APETALA3 (AP3) that showed distinct expression in male reproductive organs but not female reproductive organs. Besides being involved in the male and female reproductive parts, these genes were also recruited for petal identity in Arabidopsis [59]. We also found petal expression for them in B. rapa flowers.

Genes involved in $C$ and $D$ functions are from the monophyletic AG subfamily. All $A G$ family genes in $B$. rapa had higher expression in female organs than in male. $\mathrm{C}$ and D class genes like STK/AGL11, SHATTERPROOF1 (SHP1), and $S H P 2$, are together required for ovule identity [52]. Close homologs of SEP (SEPALLATA) genes from the AGL2-like subfamily in $B$. rapa showed widespread expression mainly in the aboveground parts; this is suggestive of their involvement in organ development. Pelaz et al. studied triple mutants of Arabidopsis SEP family genes (SEP1, SEP2 and SEP3) and found that their redundant functions are required for petal, stamen and carpel development and to prevent indeterminate growth of the flower meristem [20]. Genes of this family have been identified in fruits during the ripening stage of grapevine [13]. Similarly, two tomato SEP genes, TM29 and LeMADSRIN, appear to play roles in tomato fruit development [60]. The AGL12 subfamily has three members in B. rapa, two in poplar and one each in Arabidopsis and grapevine. Genes from this subfamily have found to play roles in the regulation of cell cycle in root meristems and as promoters of flowering transition through up-regulation of $S O C 1$, FLOWERING LOCUS T (FT) and LEAFY (LFY) [27].

We found both reproductive and vegetative expression of AGL15 subfamily genes in B. rapa, as in Arabidopsis, whereas they were restricted to the flower buds, flowers and fruits in grapevine [13]. AGL15 and AGL18 are proposed to function as repressors of floral transition, acting upstream of FT and probably in combination with other floral repressors like SVP or FLC [61]. Our results regarding AGL17-like genes correspond with their expression in Arabidopsis, where they are expressed primarily in roots, which indicate that they might function in $B$. rapa root development. The flower bud expression of the AGL17like genes in B. rapa is also consistent with the assumption of a flowering promoter role for AGL17, which could 
participate in the photoperiodic induction of $A P 1$ and $L F Y$ independent of FT [62].

Predominant expression of B. rapa MIKC* genes in the young bud stage demonstrates their importance in male reproductive organ development. Our results contrast with those for AtMIKC*, for which Verelst el al. reported predominant expression during late stages (mature pollen grain stage) of pollen development [47].

Predominant expression of three TT16 homologs (GGM13-like genes) in the early stage of female reproductive growth demonstrates their importance in the development of this organ (Figure 4e). These findings are similar to that of a previous investigation in Arabidopsis, where GGM13-like gene expression was observed in female reproductive organs, especially in ovules, which is also consistent with the situation in gymnosperms and other angiosperms [63]. Moreover, TT16 from Arabidopsis is the only GGM13-like gene for which a mutant phenotype is known. Analysis of this mutant revealed that TT16 is involved in the specification of endothelial cells and control of flavonoid biosynthesis in seed coat [23].

\section{Role of MADS-box genes in vegetative tissue development}

Transcription of a number of MADS-box genes outside flowers and fruits as well as an increasing number of mutant and transgenic flowering plants suggest that members of this gene family play regulatory roles during vegetative development also, such as in embryo, root and leaf development $[1,10]$. The existence of MADSbox genes in gymnosperms, ferns, and mosses, which do not form flowers or fruits, further demonstrates the role of these genes in plants is not restricted to flower or fruit development $[12,64]$.

All homologs from the AGL17-like clade in the B. rapa genome were predominantly expressed in roots and some of them were detected in stem and leaf tissues as well. Reports from different studies indicate that AGL17-like genes show unusually diverse expression patterns in roots, pollen, leaf guard cells and trichomes. It is likely that the ancestral AGL17-like gene had an expression domain restricted to vegetative tissues [1].

In Arabidopsis, AGL18 and AGL15 showed high expression in roots, flowers, siliques, and significant expression was also observed in stem and leaves. Moreover, AGL18 was detected up to the heart stage of embryo development but not in the developing embryos at any stage [1]. Accordingly, we can also predict that BrMADS2, 3, 4 and 85 in B. rapa, as putative orthologs of $A G L 18$, might play roles in vegetative tissue development.

TM3-like genes in Arabidopsis (AGL14 and AGL19) have been reported to function in the roots (in the columella, lateral root cap, and epidermal cells of the meristematic region and in the central cylinder of the mature roots) $[1,13]$. SOC1, a floral pathway integrator, expressed most abundantly in aboveground parts, is repressed by another MADS-box gene, the floral transition repressor $F L C$, which is involved in vernalization $[65,66]$.

The ubiquitous expression of some $B$. rapa FLC genes corresponds to that of their Arabidopsis homologs. Kim et al. reported that the expression of three $B r F L C$ genes (BrFLC1, BrFLC2, BrFLC3) was associated with flowering time and concluded that $B r F L C$ genes act similarly to $A t F L C$ and ultimately help in controlling of flowering time in $B$. rapa and other crops as well to produce higher vegetative yields [40].

The ubiquitous expression of B. rapa STMADS11-like genes suggests that these might be good candidates to play regulatory roles. Reports on STMADS11 genes from different crops demonstrated that they play important roles in developing vegetative tissues. For example, JOINTLESS, a tomato (Solanum lycopersicum) MADS-box gene is required for the development of a functional abscission zone in tomato flowers [67]. Transcripts of the potato MADS-box genes STMADS11 and STMADS16 are present in all vegetative tissues of potato, including roots and new tubers, but are not detected in floral organs [68].

BrMADS SQUA-like genes expressed in the vegetative tissues might have some regulatory roles related to vegetative tissue development. Potato MADS-box 1 (POTM1) a potato SQUA-like gene, exhibited widespread expression in actively growing tissues such as meristems, roots, new leaves and new tubers [69].

\section{Stress responsive MADS-box genes in B. rapa}

MADS-box genes have already been identified to play roles under low temperature stress in tomato [70], while seven MADS-box genes have been demonstrated to take part in stress (cold, salt and drought) responses in rice [35]. Our qPCR analysis revealed differential expression of thirteen MADS-box genes (BrMADS11, 12, 14, 20, 23, $24,36,38,39,40,44,103$, and 127) in response to cold stress (Figure 6a). We observed, expression patterns some of these potential genes (BrMADS23, 24, 36, 38, 44 and 103) were not consistent with the microarray results. However, we identified some candidate stress-resistance and stress-susceptibility genes based on up- and downregulation of the genes between two inbred lines, Chiifu and Kenshin, of B. rapa. We found that Chiifu, as a coldresistant line, showed more up-regulation of MADS-box genes than did Kenshin in response to cold stress via qPCR analysis. The exceptions were BrMADS24 and 36, which exhibited much higher up-regulation in Kenshin than in Chiifu and these two genes might be related to cold susceptibility in Kenshin. The highly expressed MADS-box genes in Chiifu might be involved in cold resistance, while their inactivity or very low activity in Kenshin might play a role in the cold susceptibility of 
that line. We also identified six (BrMAD12, 14, 20, 39,103, and 127) and eight (BrMADS11, 12, 14, 24, $38,44,103$, and 127) MADS-box genes as differentially expressed in response to salt and drought, respectively (Figure 6b \& 6c). Similar phenomena as in cold stress were also observed in case of resistance against salt and drought stresses between the two lines of B. rapa. Finally, we found BrMADS12, 14, 103 and 127 to be co-responsive against all three stresses, suggesting that these genes might have multiple stress resistance related functions in B. rapa. Among the stress-induced genes, eleven were from the important MIKC $C^{\mathrm{C}}$ group, which is well known for regulatory roles in growth and development of different higher plants. FLC is repressed by cold and others FLC-like genes are also responsive to temperature in different ways [71]. We also identified three cold responsive B. rapa FLC-like genes (BrMADS11, 12 and 14) from this clade. In rice, all seven stressresponsive genes were also from $\mathrm{MIKC}^{\mathrm{C}}$ [35]. Likewise, in wheat, a large number of genes involved in flower development are associated with abiotic stress responses [34]. Moreover, we found two $\mathrm{M} \alpha$ genes (BrMADS103 and 127) to show stress responsiveness in $B$. rapa, which has not been reported in any plant yet. Our findings here serve as an important resource guiding specific investigations on the stress resistance of $B$. rapa related to MADSbox genes.

\section{Conclusion}

This is a comprehensive and systemic analysis of MADSbox TFs in B. rapa wherein we demonstrated their expression patterns in different growth organs and examined their responses to various abiotic stresses as well. Our data set presented here, which includes likely $\mathrm{B}$ and $\mathrm{C}$ function genes that display male organ-specific expression, should be an important resource for study of male sterility in $B$. rapa. Furthermore, the stress-responsive genes described in this study might be exploited for molecular breeding of $B$. rapa. The results presented here also facilitate selection of appropriate candidate genes for further functional characterization.

\section{Methods}

\section{Identification of MADS-box genes}

A search of SWISSPROT annotations at the Brassica database (BRAD) was conducted using keyword 'MADSbox' (http://brassicadb.org/brad/) [37]. Protein and CDS of the resulting candidate $B$. rapa MADS-box genes were obtained from the Brassica database (http://brassicadb.org/brad/) [37]. To confirm the presence of a MADSbox domain, the web tool from EMBL (http://smart.embl.de/smart/set_mode.cgi?GENOMIC=1) and homology searches using the Basic Local Alignment Search Tool (BLAST; http://www.ncbi.nlm.nih.gov/BLAST/) were performed on the set of candidate MADS-box genes in B. rapa. The primary structure of the genes was analyzed using protParam (http://expasy.org/tools/protparam.html). The number of introns and exons was determined by manually aligning the CDS sequences with the genomic sequences using ClustalW [72] and with the 'Gene Structure Display Server' (GSDS) web tool [73].

\section{Phylogenetic analysis of MADS-box proteins}

B. rapa MADS-box proteins were aligned using ClustalX with those of rice and Arabidopsis. [74]. The phylogenetic trees were generated with MEGA6.06 using the Neighbor -Joining (NJ) algorithm [75]. Bootstrap analysis with 1,000 replicates was used to evaluate the significance of the nodes. Pairwise gap deletion mode was used to ensure that the divergent domains could contribute to the topology of the NJ tree. For generating alternative phylogenetic trees all the protein sequences were aligned in ClustalW using default parameters [72] and the phylogenetic trees were constructed using MEGA6.06 [75].

\section{Analysis of conserved motifs in MADS-box proteins}

The MADS-box protein sequences were analyzed using the MEME software (Multiple Em for Motif Elicitation, V4.9.0) [76]. A MEME search was executed with the following parameters: (1) optimum motif width $\geq 6$ and $\leq 200$; (2) maximum number of motifs to identify $=10$.

\section{Chromosomal locations and gene duplication of MADS-box genes}

All MADS-box genes of $B$. rapa were BLAST searched (http://www.ncbi.nlm.nih.gov/BLAST/) against each other to identify duplicate genes, with the criteria that both the similarity and query coverage percentage of the candidate genes were $>80 \%$ [77]. Positional information for all candidate MADS-box genes along the 10 chromosomes of B. rapa were obtained from the Brassica database (http:// brassicadb.org/brad/) [37]. The map of all genes along the 10 chromosomes and duplication lines among genes were drawn manually.

\section{Analysis of syntenic relationships}

To identify Arabidopsis orthologues of MADS-box genes in B. rapa, each candidate MADS-box gene nucleotide sequence was employed in a BLASTX search of the NCBI database (http://blast.ncbi.nlm.nih.gov/Blast.cgi) using $A$. thaliana as reference organism and the best hit $A$. thaliana homologue was considered to be the orthologue of the $B$. rapa MADS-box gene.

\section{Collection and preparation of plant material}

B. rapa 'SUN-3061' plants were grown in the Department of Horticulture, Sunchon National University, Korea. For the organ study, fresh roots, stems, leaves and flower buds 
were harvested, frozen immediately in liquid nitrogen, and stored at $-80^{\circ} \mathrm{C}$ for RNA isolation. For the three abiotic stress treatments, two inbred lines of B. rapa ssp. pekinensis 'Chiifu' and 'Kenshin' were used. Chiifu originated in temperate regions, whereas Kenshin originated in subtropical and tropical regions [78]. Plants were cultivated under aseptic conditions in semisolid media for $10 \mathrm{~d}$, after which plants were transferred into liquid media to minimize stress during the treatment time. Three stress treatments, cold, drought and salt, were administered over 8 time periods $(0 \mathrm{~h}, 30 \mathrm{~min}, 1 \mathrm{~h}, 4 \mathrm{~h}, 8 \mathrm{~h}, 12 \mathrm{~h}, 24 \mathrm{~h}$ and $48 \mathrm{~h}$ ). Plant samples were transferred to the incubator at $4^{\circ} \mathrm{C}$ to induce cold stress. Drought/desiccation stress was simulated by drying the plants on Whatmann $3 \mathrm{~mm}$ filter sheets. To induce salt stress, plant samples were transferred to rectangular petri dishes $(72 \times 72 \times 100 \mathrm{~mm})$ with medium containing $200 \mathrm{mM} \mathrm{NaCl}$ for the designed time courses [35]. In each stress experiment, leaves of treated samples were collected and processed to study the expression of different MADS-box genes.

\section{Microarray expression analysis}

Br135K microarray (Brapa_V3_microarray, 3'-Tiling microarray) is a high-density DNA array prepared with Maskless Array Synthesizer (MAS) technology by NimbleGen (http://www.nimblegen.com/). Probes are designed from 41,173 genes of B. rapa accession Chiifu-401-42, a Chinese cabbage [36]. For the microarray experiment four-weekold $B$. rapa inbred lines, Chiifu and Kenshin, were treated with cold or freezing stress $\left(4^{\circ} \mathrm{C}, 0^{\circ} \mathrm{C},-2^{\circ} \mathrm{C}\right.$ and $\left.-4^{\circ} \mathrm{C}\right)$. Stress treatments were applied for $2 \mathrm{~h}$ and immediately after stress, total and polysomal RNA was extracted from the leaf tissues using the RNeasy Mini kit (Qiagen, USA). RNA protect reagent (Qiagen) and DNA was removed by on-column DNase digestion with the RNase-Free DNase set (Qiagen). Labeling was performed by NimbleGen Systems Inc. (Madison, WI USA), following their standard operating protocol (www.nimblegen.com). The raw data (pair file) was subjected to RMA (Robust Multi-Array Analysis) [79], quantile normalization [80], and background correction as implemented in the NimbleScan software package, version 2.4.27 (Roche NimbleGen, Inc.). To assess the reproducibility of the microarray analysis, we repeated the experiment three times with independently prepared total RNA. The complete microarray data have been deposited in Omics database of NABIC (http:// nabic.rda.go.kr) as enrolled number, NC-0024-000001 NC-0024-000012.

\section{RT-PCR expression analysis}

RT-PCR was conducted using an AMV one step RT-PCR kit (Takara, Japan). Specific primers for all genes were used in RT-PCR, and Actin primers for B. rapa (FJ969844) were used as a control (Additional file 3: Table S4). PCR was conducted using 50 ng cDNA from the plant and flower organs as templates in master mixes composed of $20 \mathrm{pmol}$ each primer, $150 \mu \mathrm{M}$ each dNTP, $1.2 \mathrm{U}$ Taq polymerase, $1 \mathrm{x}$ Taq polymerase buffer and double-distilled $\mathrm{H}_{2} \mathrm{O}$ diluted to a total volume of $20 \mu \mathrm{L}$ in $0.5-\mathrm{mL}$ PCR tubes. The samples were subjected to the following conditions: pre-denaturing at $94^{\circ} \mathrm{C}$ for $5 \mathrm{~min}$, followed by 30 cycles of denaturation at $94^{\circ} \mathrm{C}$ for $30 \mathrm{~s}$, annealing at $55^{\circ} \mathrm{C}$ for $30 \mathrm{~s}$ and extension at $72^{\circ} \mathrm{C}$ for $45 \mathrm{~s}$, with a final extension for $5 \mathrm{~min}$ at $72^{\circ} \mathrm{C}$.

\section{qPCR expression analysis}

Real-time quantitative PCR was performed using $1 \mu \mathrm{L}$ cDNA in a $20-\mu \mathrm{L}$ reaction volume employing iTaqTM SYBR $^{\circ}$ Green Super-mix with ROX (California, USA). The specific primers used for real-time PCR are listed in Additional file 4: Table S5. The conditions for real-time PCR were as follows: $10 \mathrm{~min}$ at $95^{\circ} \mathrm{C}$, followed by $40 \mathrm{cy}$ cles at $95^{\circ} \mathrm{C}$ for $20 \mathrm{~s}, 58^{\circ} \mathrm{C}$ for $20 \mathrm{~s}$, and $72^{\circ} \mathrm{C}$ for $25 \mathrm{~s}$. The fluorescence was measured following the last step of each cycle, and three replicates were used for each sample. Amplification detection and data analysis were conducted using LightCycler96 (Roche, Germany).

\section{Additional files}

Additional file 1: Table S1. Total number of MADS-box genes within each group of Arabidopsis, Rice, Soybean, Maize, Sorghum and B. rapa. Table S2. Homology analysis of 167 MADS-box genes in B. rapa. Table S3. Synteny table showing $A$. thaliana orthologous MADS-box gene pairs in B. rapa.

Additional file 2: Figure S1. (a) Phylogenetic analysis of 138 type I MADS-box proteins from B.rapa (67), Arabidopsis (43) and Rice (28). Figure S1. (b) Phylogenetic analysis of type II B. rapa, Rice and Arabidopsis MADS-box proteins.181 type II MADS-box proteins from B. rapa (100), Arabidopsis (43) and rice (38) showing $13 \mathrm{MIKC}^{\mathrm{C}}$ clades and MIKC $C^{*}$ group as marked in the figure. FigureS2. Exon-intron structures of B.rapa MADS-box genes. Green boxes, exons; lines, introns. Five groups $M_{1 K C^{c}}, M_{K C}^{*}, M a, M \beta$ and $M y$ are labeled under type $\|$ and type I. Size of each gene can be estimated using the scale (in Kilobase; Kb) on the top of the figure. Figure S3. Distribution of Conserved motifs in Brassica rapa MADS-box type I proteins identified using MEME search tool. Schematic representation of motifs identified in Brapa MADS-box type I proteins using MEME motif search tool for each group ( $M a, M \beta$ and $M \gamma$ ) given separately. Different motifs are indicated by different colors, and the names of all members are shown on the left side of the figure. The order of the motifs corresponds to the position of the motifs in individual protein sequences. Figure S4. Microarray expression analysis of MADS-box genes in B. rapa under different temperature treatment. Here $C$ and $\mathrm{K}$ indicates Chiifu and Kenshin, were treated under five (5) temperatures as control $(\mathrm{C} 1 \& \mathrm{~K} 1), 4^{\circ} \mathrm{C}(\mathrm{C} 2 \& \mathrm{~K} 2), 0^{\circ} \mathrm{C}$ $(\mathrm{C} 3 \& \mathrm{~K} 3),-2^{\circ} \mathrm{C}(\mathrm{C} 4 \& \mathrm{~K} 4)$, and $-4^{\circ} \mathrm{C}(\mathrm{C} 5 \& \mathrm{~K} 5)$. Color bar at the top representing differential expression like purple representing medium level expression where pink to white showing low to no expression.

Additional file 3: Table S4. RT-PCR primer list of BrMADSs.

Additional file 4: Table S5. Primers for qantitative PCR of BrMADSs.

\section{Abbreviations}

TF: Transcription Factor; BRAD: Brassica database; ORF: Open Reading Frame; MEME: Multiple Em for Motif Elicitation; WGD: Whole Genome Duplication; GSDS: Gene Structure Display Server; MAS: Maskless Array Synthesizer; RMA: Robust Multi-Array Analysis; NRF: National Research Foundation of Korea. 


\section{Competing interests}

The authors declare that they have no competing interests.

\section{Authors' contributions}

GS and JP carried out the computational analysis, plant culture and sample preparation for microarray experiments, performed RT-PCR and real-time $P C R$, analyzed the data and drafted the manuscript. HJ collected primary data regarding genes and cultured plants and collected samples for organ study. NUA and MAK designed the stress experiments and cultured the plants and gave stress treatments to the two B. rapa inbred lines 'Chiifu' and 'Kenshin'. $M C, Y H$ and $Y C$ did the microarray experiments and analyzed the results. MW revised the final version of the manuscript and gave suggestions for improving it. IN designed and participated in all the experiments and assisted in improving the technical sites of the project. All authors have read and approved the final manuscript.

\section{Acknowledgments}

We thank two anonymous reviewers for their insightful comments. This research was jointly supported by Basic Science Research Program through the National Research Foundation of Korea (NRF) funded by the Ministry of Education, Science and Technology (2012R1A1A2044500) and Golden Seed Project (Center for Horticultural Seed Development, No. 213003-04-2-SB110), Ministry of Agriculture, Food and Rural Affair (MAFRA), Ministry of Oceans and Fisheries (MOF), Rural Development Administration (RDA) and Korea Forest Service (KFS).

\section{Author details}

${ }^{1}$ Department of Horticulture, Sunchon National University, 413 Jungangno, Suncheon, Jeonnam 540-742, Republic of Korea. ${ }^{2}$ Department of Agricultural Education, Sunchon National University, 413 Jungangno, Suncheon, Jeonnam 540-742, Republic of Korea. ${ }^{3}$ Department of Biology, Chungnam National University, 96 Daehangno, Gung-dong, Yuseong-gu, Daejeon 305-764, Republic of Korea. ${ }^{4}$ Department of Crop Science, Chungbuk National University, 410 Seongbongro, Heungdokgu, Cheongju 361-763, Republic of Korea. ${ }^{5}$ Laboratory of Plant Reproductive Genetics, Graduate School of Life Sciences, Tohoku University, 2-1-1, Katahira, Aoba-ku, Sendai 980-8577, Japan.

\section{Received: 12 June 2014 Accepted: 17 February 2015} Published online: 14 March 2015

\section{References}

1. Alvarez-Buylla ER, Liljegren SJ, Pelaz S, Gold SE, Burgeff C, Ditta GS, et al. MADS-box gene evolution beyond flowers: expression in pollen, endosperm, guard cells, roots and trichomes. Plant J. 2000;24(4):457-66.

2. Ma H, DePamphilis C. The ABCs of floral evolution. Cell. 2000;101(1):5-8.

3. Messenguy F, Dubois E. Role of MADS box proteins and their cofactors in combinatorial control of gene expression and cell development. Gene. 2003:316:1-21

4. Parenicova L, de Folter S, Kieffer M, Horner DS, Favalli C, Busscher J, et al. Molecular and phylogenetic analyses of the complete MADS-box transcription factor family in Arabidopsis. Plant Cell Online. 2003;15(7):1538-51.

5. De Folter $S$, Angenent GC. Trans meets cis in MADS science. Trends Plant Sci. 2006;11(5):224-31.

6. Norman C, Runswick M, Pollock R, Treisman R. Isolation and properties of CDNA clones encoding SRF, a transcription factor that binds to the c-fos serum response element. Cell. 1988;55(6):989-1003.

7. Alvarez-Buylla ER, Pelaz S, Liljegren SJ, Gold SE, Burgeff C, Ditta GS, et al. An ancestral MADS-box gene duplication occurred before the divergence of plants and animals. Proc Natl Acad Sci U S A. 2000;97(10):5328-33.

8. Kofuji R, Sumikawa N, Yamasaki M, Kondo K, Ueda K, Ito M, et al. Evolution and divergence of the MADS-box gene family based on genome-wide expression analyses. Mol Biol Evol. 2003;20(12):1963-77.

9. Becker A, Theißen G. The major clades of MADS-box genes and their role in the development and evolution of flowering plants. Mol Phylogenet Evol. 2003;29(3):464-89.

10. Theißen G, Kim J, Saedler H. Classification and phylogeny of the MADS-box multigene family suggest defined roles of MADS-box gene subfamilies in the morphological evolution of eukaryotes. J Mol Evol. 1996;43(5):484-516.
11. Yang $Y$, Fanning $L$, Jack $T$. The $K$ domain mediates heterodimerization of the rabidopsis floral organ identity proteins, APETALA3 and PISTILLATA. Plant J. 2003;33(1):47-59.

12. Henschel K, Kofuji R, Hasebe M, Saedler H, Munster T, Theißen G. Two ancient classes of MIKC-type MADS-box genes are present in the moss Physcomitrella patens. Mol Biol Evol. 2002;19(6):801-14.

13. Diaz-Riquelme J, Lijavetzky D, Martinez-Zapater JM, Carmona MJ. Genome-wide analysis of MIKCC-type MADS box genes in grapevine. Plant Physiol. 2009;149(1):354-69.

14. Honma T, Goto K. Complexes of MADS-box proteins are sufficient to convert leaves into floral organs. Nature. 2001;409(6819):525-9.

15. Rounsley SD, Ditta GS, Yanofsky MF. Diverse roles for MADS-box genes in Arabidopsis development. Plant Cell. 1995;7(8):1259-69.

16. Saedler H, Becker A, Winter KU, Kirchner C, Theissen G. MADSbox genes are involved in floral development and evolution. Acta Biochim Pol. 2001;48(2):351-8.

17. Moore S, Vrebalov J, Payton P, Giovannoni J. Use of genomics tools to isolate key ripening genes and analyse fruit maturation in tomato. J Exp Bot. 2002;53(377):2023-30.

18. Michaels SD, Ditta G, Gustafson-Brown C, Pelaz S, Yanofsky M, Amasino RM AGL24 acts as a promoter of flowering in Arabidopsis and is positively regulated by vernalization. Plant J. 2003;33(5):867-74.

19. Ferrandiz C, Gu Q, Martienssen R, Yanofsky MF. Redundant regulation of meristem identity and plant architecture by FRUITFULL, APETALA1 and CAULIFLOWER. Development. 2000;127(4):725-34.

20. Pelaz S, Ditta GS, Baumann E, Wisman E, Yanofsky MF. B and C floral organ identity functions require SEPALLATA MADS-box genes. Nature. 2000;405(6783):200-3.

21. Gu Q, Ferra'ndiz C, Yanofsky MF, Martienssen R. The FRUITFULL MADS-box gene mediates cell differentiation during Arabidopsis fruit development. Development. 1998;125(8):1509-17.

22. Liljegren SJ, Ditta GS, Eshed Y, Savidge B, Bowman JL, Yanofsky MF. SHATTERPROOF MADS-box genes control seed dispersal in Arabidopsis. Nature. 2000;404(6779):766-70.

23. Nesi N, Debeaujon I, Jond C, Stewart AJ, Jenkins GI, Caboche M, et al. The TRANSPARENT TESTA16 locus encodes the ARABIDOPSIS BSISTER MADS domain protein and is required for proper development and pigmentation of the seed coat. Plant Cell. 2002;14(10):2463-79.

24. Ditta G, Pinyopich A, Robles P, Pelaz S, Yanofsky MF. The SEP4 gene of Arabidopsis thaliana functions in floral organ and meristem identity. Curr Biol. 2004;14(21):1935-40.

25. Theissen G, Melzer R. Molecular mechanisms underlying origin and diversification of the angiosperm flower. Ann Bot (Lond). 2007;100(3):603-19.

26. Burgeff C, Liljegren S, Tapia-Lopez R, Yanofsky M, Alvarez-Buylla E. MADS-box gene expression in lateral primordia, meristems and differentiated tissues of Arabidopsis thaliana roots. Planta. 2002;214(3):365-72.

27. Tapia-Lopez R, Garcia-Ponce B, Dubrovsky JG, Garay-Arroyo A, Pe'rez-Ruiz RV, Kim SH, et al. An AGAMOUS-related MADS-box gene, XAL1 (AGL12), regulates root meristem cell proliferation and flowering transition in Arabidopsis. Plant Physiol. 2008;146(3):1182-92.

28. Bemer M, Heijmans K, Airoldi C, Davies B, Angenent GC. An atlas of type I MADS box gene expression during female gametophyte and seed development in Arabidopsis. Plant Physiol. 2010;154(1):287-300.

29. Talalay P, Fahey W. Phytochemicals from cruciferous plants protect against cancer by modulating carcinogen metabolism. J Nutr. 2001;131(11):3027S-33.

30. Brassica Genome Gateway. [http://brassica.bbsrc.ac.uk]

31. Yang TJ, Kim JS, Lim KB, Kwon SJ, Kim JA, Jin, M, et al. The Korea Brassica Genome Project: A glimpse of the Brassica genome based on comparative genome analysis with Arabidopsis. Comparative and functional genomics. 2005;6(3):138-46.

32. Song XM, Huang ZN, Duan WK, Ren J, Liu TK, Li Y, et al. Genome-wide analysis of the bHLH transcription factor family in Chinese cabbage (Brassica rapa ssp. pekinensis). Mol Genet Genomics. 2014;289(1):77-91.

33. Nam J, Ma H, Nei M. Antiquity and evolution of the MADS-box gene family controlling flower development in plants. Mol Biol Evol. 2003;20(9):1435-47.

34. Tardif G, Kane NA, Adam H, Labrie L, Major G, Gulick P, et al. Interaction network of proteins associated with abiotic stress response and development in wheat. Plant Mol Biol. 2007;63(5):703-18.

35. Arora R, Agarwal P, Ray S, Singh AK, Singh VP, Tyagi AK, et al. MADS-box gene family in rice: genome-wide identification, organization and expression profiling during reproductive development and stress. BMC Genomics. 2007;8(1):242. 
36. Wang $X$, Wang $H$, Wang J, Sun $R$, Wu J, Liu S, et al. The genome of the mesopolyploid crop species Brassica rapa. Nat Genet. 2011;43(10):1035-9.

37. Cheng F, Liu S, Wu J, Fang L, Sun S, Liu B, et al. BRAD, the genetics and genomics database for Brassica plants. BMC Plant Biol. 2011;11(1):136.

38. Shu Y, Yu D, Wang D, Guo D, Guo C. Genome-wide survey and expression analysis of the MADS-box gene family in soybean. Mol Biol Rep. 2013:40(6):3901-11.

39. Zhao Y, Li X, Chen W, Peng X, Cheng X, Zhu S, et al. Whole-genome survey and characterization of MADS-box gene family in maize and sorghum. Plant Cell Tissue Organ Cult. 2010;105(2):159-73.

40. Kim SY, Park BS, Kwon SJ, Kim J, Lim MH, Park YD, et al. Delayed flowering time in Arabidopsis and Brassica rapa by the overexpression of FLOWERING LOCUS C (FLC) homologs isolated from Chinese cabbage (Brassica rapa L. ssp. pekinensis). Plant Cell Rep. 2007;26(3):327-36.

41. Flagel LE, Wendel JF. Gene duplication and evolutionary novelty in plants. New Phytol. 2009;183(3):557-64.

42. Sankoff D, Zheng C, Zhu Q. The collapse of gene complement following whole genome duplication. BMC Genomics. 2010;11(1):313.

43. Cheng F, Wu J, Fang L, Sun S, Liu B, Lin K, et al. Biased gene fractionation and dominant gene expression among the subgenomes of Brassica rapa. PLoS One. 2012;7(5):e36442.

44. Tang H, Woodhouse MR, Cheng F, Schnable JC, Pedersen BS, Conant G, et al. Altered patterns of fractionation and exon deletions in Brassica rapa support a two-step model of paleohexaploidy. Genetics. 2012;190(4):1563-74

45. Mun JH, Kwon SJ, Yang TJ, Seol YJ, Jin M, Kim JA, et al. Genome-wide comparative analysis of the Brassica rapa gene space reveals genome shrinkage and differential loss of duplicated genes after whole genome triplication. Genome Biol. 2009;10(10):R111.

46. Kaufmann K, Melzer R, Theissen G. MIKC-type MADS-domain proteins: structural modularity, protein interactions and network evolution in land plants. Gene. 2005;347(2):183-98.

47. Verelst W, Saedler H, Munster T. MIKC* MADS-protein complexes bind motifs enriched in the proximal region of late pollen-specific Arabidopsis promoters. Plant Physiol. 2007;143(1):447-60

48. Hartmann U, Hohmann S, Nettesheim K, Wisman E, Saedler H, Huijser P. Molecular cloning of SVP: a negative regulator of the floral transition in Arabidopsis. Plant J. 2000;21(4):351-60

49. Yu H, Xu Y, Tan EL, Kumar PP. AGAMOUS-LIKE 24, a dosage-dependent mediator of the flowering signals. Proc Natl Acad Sci. 2002;99(25):16336-41.

50. Winter KU, Weiser C, Kaufmann K, Bohne A, Kirchner C, Kanno A, et al. Evolution of class B floral homeotic proteins: obligate heterodimerization originated from homodimerization. Mol Biol Evol. 2002;19(5):587-96.

51. Walden AR, Wang DY, Walter C, Gardner RC. A large family of TM3 MADS-box cDNAs in Pinus radiata includes two members with deletions of the conserved K domain. Plant Sci. 1998;138:167-76.

52. Winter K-U, Becker A, Munster T, Kim JT, Saedler H, Theißen G. MADS-box genes reveal that gnetophytes are more closely related to conifers than to flowering plants. Proc Natl Acad Sci U S A. 1999;96:7342-7.

53. Lee J, Lee I. Regulation and function of SOC1, a flowering pathway integrator. J Exp Bot. 2010;61(9):2247-54

54. Pinyopich A, Ditta GS, Savidge B, Liljegren SJ, Baumann E, Wisman E, et al. Assessing the redundancy of MADS-box genes during carpel and ovule development. Nature. 2003;424:85-8.

55. Mandel MA, Gustafson-Brown C, Savidge B, Yanofsky MF. Molecular characterization of the Arabidopsis floral homeotic gene APETALA1. Nature. 1992;360:273-7.

56. Immink RG, Tonaco IA, de Folter $S$, Shchennikova A, van Dijk AD, Busscher-Lange J, et al. SEPALLATA3: the'glue'for MADS box transcription factor complex formation. Genome Biol. 2009;10(2):R24.

57. Nam J, Kim J, Lee S, An G, Ma H, Nei M. Type I MADS-box genes have experienced faster birth-and-death evolution than type II MADS-box genes in angiosperms. Proc Natl Acad Sci U S A. 2004;101(7):1910-5

58. $\mathrm{Ma} \mathrm{H}$. The unfolding drama of flower development: recent results from genetic and molecular analyses. Genes Dev. 1994;8(7):745-56.

59. Winter KU, Saedler H, Theißen G. On the origin of class B floral homeotic genes: functional substitution and dominant inhibition in Arabidopsis by expression of an ortholog from the gymnosperm Gnetum. Plant J. 2002;31(4):457-75
60. Vrebalov J, Ruezinsky D, Padmanabhan V, White R, Medrano D, Drake R, et al. A MADS-box gene necessary for fruit ripening at the tomato ripening-inhibitor (rin) locus. Science. 2002;296(5566):343-6.

61. Adamczyk BJ, Lehti-Shiu MD, Ferna'ndez DE. The MADS domain factors AGL15 and AGL18 act redundantly as repressors of the floral transition in Arabidopsis. Plant J. 2007:50(6):1007-19.

62. Han P, Garcia-Ponce B, Fonseca-Salazar G, Alvarez-Buylla ER, Yu H. AGAMOUS- LIKE 17, a novel flowering promoter, acts in a FT independent photoperiod pathway. Plant J. 2008;55(2):253-65

63. Becker A, Kaufmann K, Freialdenhoven A, Vincent C, Li MA, Saedler $H$, et al. A novel MADS-box gene subfamily with a sister-group relationship to class B floral homeotic genes. Mol Genet Genomics. 2002;266(6):942-50.

64. Krogan NT, Ashton NW. Ancestry of plant MADS-box genes revealed by bryophyte (Physcomitrella patens) homologues. New Phytol. 2000;147(3):505-17.

65. Liu C, Chen H, Er HL, Soo HM, Kumar PP, Han JH, et al. Direct interaction of AGL24 and SOC1 integrates flowering signals in Arabidopsis. Development. 2008;135(8):1481-91.

66. Deng W, Ying H, Helliwell CA, Taylor JM, Peacock WJ, Dennis ES FLOWERING LOCUS C (FLC) regulates development pathways throughout the life cycle of Arabidopsis. Proc Natl Acad Sci. 2011;108(16):6680-5.

67. Mao L, Begum D, Chuang H-W, Budiman MA, Szymkowiak EJ, Irish EE, et al. JOINTLESS is a MADS-box gene controlling tomato flower abscission zone development. Nature. 2000:406(6798):910-3.

68. Carmona MJ, Ortega N, Garcia-Maroto F. Isolation and molecular characterization of a new vegetative MADS-box gene from Solanum tuberosum L. Planta. 1998;207(2):181-8.

69. Kang S-G, Hannapel DJ. Nucleotide sequences of novel potato (Solanum tuberosum L.) MADS-box cDNAs and their expression in vegetative organs. Gene. 1995;166(2):329-30.

70. Lozano R, Angosto T, Gomez P, Payan C, Capel J, Huijser P, et al. Tomato flower abnormalities induced by low temperatures are associated with changes of expression of MADS-Box genes. Plant Physiol. 1998;117(1):91-100.

71. Alexandre CM, Hennig L. FLC or not FLC: the other side of vernalization. J Exp Bot. 2008;59(6):1127-35.

72. Thompson JD, Higgins DG, Gibson TJ. CLUSTAL W: improving the sensitivity of progressive multiple sequence alignment through sequence weighting, position-specific gap penalties and weight matrix choice. Nucleic Acids Res. 1994;22(22):4673-80.

73. Guo AY, Zhu QH, Chen X, Luo JC. GSDS: a gene structure display server. Yi Chuan. 2007;29(8):1023-6.

74. Thompson JD, Gibson TJ, Plewniak F, Jeanmougin F, Higgins DG. The CLUSTAL_X windows interface: flexible strategies for multiple sequence alignment aided by quality analysis tools. Nucleic Acids Res. 1997;25(24):4876-82

75. Tamura K, Stecher G, Peterson D, Filipski A, Kumar S. MEGA6: Molecular Evolutionary Genetics Analysis Version 6.0. Mol Biol Evol. 2013;30:2725-9.

76. Bailey TL, Williams N, Misleh C, Li WW. MEME: discovering and analyzing DNA and protein sequence motifs. Nucleic Acids Res. 2006;34 suppl 2:369-73.

77. Kong X, Lv W, Jiang S, Zhang D, Cai G, Pan J, et al. Genome-wide identification and expression analysis of calcium-dependent protein kinase in maize. BMC Genomics. 2013;14(1):433.

78. Lee J, Lim YP, Han CT, Nou IS, Hur Y. Genome-wide expression profiles of contrasting inbred lines of Chinese cabbage, Chiifu and Kenshin, under temperature stress. Genes Genomics. 2013;35(3):273-88.

79. Irizarry RA, Hobbs B, Collin F, Beazer-barclay YD, Antonellis KJ, Scherf U, et al. Exploration, normalization, and summaries of high density oligonucleotide array probe level data. Biostatistics. 2003;4(2):249-64.

80. Bolstad BM, Irizarry RA, Astrand M, Speed TP. A comparison of normalization methods for high density oligonucleotide array data based on variance and bias. Bioinformatics. 2003;19(2):185-93. 